\title{
Broadening the scope of uranyl photoreactivity: The oxidation of a uranyl complex anion in solid-state materials
}

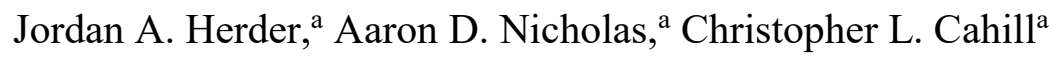 \\ ${ }^{a}$ Department of Chemistry, The George Washington University, $80022^{\text {nd }}$ Street, NW, Washington, DC, 20052, USA.
}

\begin{abstract}
Reported are the syntheses, structural characterizations and luminescence properties of three novel $\left[\mathrm{UO}_{2} \mathrm{Cl}_{4}\right]^{2}$ bearing compounds containing substituted 1,1'-dialkyl-4,4'-bipyridinum dications (i.e. viologens). These compounds undergo photoinduced luminescence quenching upon exposure to UV radiation. Kinetic analyses indicate the degree of quenching follows a secondorder rate law with a rate constant dependent on viologen substituent. This phenomenon is proposed to involve the formal transfer of one electron from the $\left[\mathrm{UO}_{2} \mathrm{Cl}_{4}\right]^{2-}$ to the viologen species. This proposed mechanism is supported through a series of calculations and computational work including Rehm-Weller analysis, time-dependent density functional theory (TD-DFT), and density of states (DOS). This work constitutes the first study of an oxidized uranyl complex anion which expands the conventional understanding of uranyl photoreactivity.
\end{abstract}

\section{Introduction}

The photoreactivity of uranium, and specifically that of the uranyl unit $\left(\mathrm{UO}_{2}{ }^{2+}\right)$, has been a fruitful area of study for actinide chemists for decades. From the characteristic luminescent emission of the uranyl cation to the chemical reactivity afforded by the excited species, researchers have probed ways to harness this unique photoreactivity. Some of our previous work has capitalized on the ability of the uranyl cation to prompt in situ peroxide formation in order to make novel families of solid-state complexes. ${ }^{1}$ Indeed this is a well-understood phenomenon whereby the uranyl cation is excited by incident light to make a strongly oxidizing species that participates in hydrogen abstraction (with a suitable substrate) and subsequently reduces ambient oxygen, ${ }^{2}$ ultimately resulting in radicalized substrate species and peroxide ions. This photoreactivity scheme has been utilized by this group ${ }^{1}$ and others ${ }^{3}$ and has resulted in rich and diverse families of uranylbearing materials.

Still more work has been committed to immobilizing the uranyl cation with ancillary ligands in order to channel its photoreactive properties in solid-state materials and metal organic 
frameworks, which allows the uranium to execute interesting and diverse functions. ${ }^{4-8}$ Some have utilized such systems for applications including the degradation of organic dyes, catalysis of organic reactions, and use in radiation sensing devices. ${ }^{4}$ What has become clear from these efforts is that uranyl photoreactivity persists in uranyl-bearing systems in both the solution state and the solid state, but the mechanisms by which these processes occur are varied. Some heterocatalytic materials allow the uranyl cation to carry out the role described by Espenson et al. (and described above). ${ }^{9}$ Other materials favor a prolonged radicalization of ligands which manifests itself as luminescence quenching, ${ }^{7}$ whereas others evoke long-lived reduced uranium metal centers. ${ }^{5}$ The mechanism proposed by Espenson et al. likely describes the majority of the activity seen in uranylbearing systems in the solution state, yet a similarly encompassing description for photoreactive solid-state materials remains elusive. Thus there is a need to synthesize new photoreactive uranyl materials and probe the relevant properties and origins thereof.

The simple uranyl tetrachloride $\left(\left[\mathrm{UO}_{2} \mathrm{Cl}_{4}\right]^{2-}\right)$ anion is a prime candidate with which to probe the photoreactivity of solid-state uranyl bearing materials. This unit has well understood optical and chemical properties, and has been studied extensively for its propensity to form supramolecular networks with organic cations such as pyridinium derivatives. ${ }^{10-12}$ Building on these efforts, we herein introduce viologens to form analogous materials, which may leverage their well-established electronic properties as utilized in catenanes, molecular switches and machines, and photochromic materials. ${ }^{13-15}$ Viologens act as one- or two-electron acceptors by providing energetically accessible $\pi^{*}$ orbitals that are reduced via photoelectron transfer (PET). PET is the process whereby an excited electron, from an electron rich donor species, is transferred to and subsequently reduces the acceptor species, forming a stable redox product. Owing to conjugation about the aromatic rings, reduced viologen radicals are particularly stable in these reactions.

Hybrid materials featuring viologens with metals often display diverse photophysical properties and have a deep literature precedent, ${ }^{16-18}$ Examples include photochromic zinc materials ${ }^{15}$ and more recently redox active lanthanide materials. ${ }^{19}$ Turning to the actinides, and the uranyl unit in particular, examples are far fewer and a search of the Cambridge Structural Database (CSD) reveals that only handful of uranyl-viologen compounds have been characterized (CCDC references: KOPMEK, KOPMIO, KOPMOU, KOPMUA, KOPNAH, NOTFOT) ${ }^{20,21}$ These examples utilize the viologen and uranyl for both their photochemical and structural contributions, yet lack an investigation of the underlying interactions between the two motifs. As such, we see 
an opportunity to synthesize uranyl-viologen bearing materials with a focus on the fundamental photoreactivity as influenced by these two units.

The synthesis and characterization of three novel uranyl compounds that feature $\left[\mathrm{UO}_{2} \mathrm{Cl}_{4}\right]^{2-}$ units paired with methyl (MV), ethyl (EV), and propyl (PV) viologen dications is reported herein. These compounds exhibit typical green uranyl emission behavior which can be quenched via prolonged irradiation with UV light. Kinetic studies demonstrate that this process occurs via a second order reaction whose rate constant is dependent on the viologen substituent. We postulate that exposure to UV light gives rise to a PET process whereby the $\left[\mathrm{UO}_{2} \mathrm{Cl}_{4}\right]^{2-}$ unit is oxidized to an air stable radical $\left[\mathrm{UO}_{2} \mathrm{Cl}_{4}\right]^{\text {n- }}$ species via electron transfer to the viologen cation. A PET mechanism is proposed and explored through a hybrid experimental and computational approach. Results demonstrate that the photoinduced redox reaction between $\left[\mathrm{UO}_{2} \mathrm{Cl}_{4}\right]^{2-}$ and viologen ion pairs is (i) thermodynamically favorable and (ii) possible owing to the band structure and excited state transitions. To our knowledge this is the first report of a long-lived radical $\left[\mathrm{UO}_{2} \mathrm{Cl}_{4}\right]^{\mathrm{n}-}$ species.

\section{Experimental}

\section{General.}

Caution!: $\mathrm{Cs}_{2} \mathrm{UO}_{2} \mathrm{Cl}_{4}$ and $\mathrm{UO}_{2}\left(\mathrm{CH}_{3} \mathrm{CO}_{2}\right)_{2}$; These compounds contain depleted $U$, and as such, standard precautions and protective measures should be taken when handing this radioactive and toxic heavy metal.

\section{Synthesis.}

Cesium Uranyl Tetrachloride. Uranyl Acetate $\left(\mathrm{C}_{4} \mathrm{H}_{6} \mathrm{O}_{6} \mathrm{U}\right)(.6240 \mathrm{~g}, 1.471 \mathrm{mmol})$ and $\mathrm{CsCl}$ (.4959 g, $2.945 \mathrm{mmol}$ ) were dissolved in $10 \mathrm{~mL}$ of a $6 \mathrm{M} \mathrm{HCl}$ solution and heated to dryness to form long yellow shard-like crystals. The product was collected and characterized by PXRD to verify product purity (compared to ICSD \#56859; Figure S1), and used for subsequent syntheses.

Methyl Viologen Dichloride Hydrate. Reagent was purchased from Sigma Aldrich (99\% purity).

Ethyl- and Propyl-Viologen Diiodide. The corresponding alkyl iodide, ethyl iodide $\left(\mathrm{C}_{2} \mathrm{H}_{5} \mathrm{I}\right)$ $(.35 \mathrm{~mL}, .68 \mathrm{~g}, 4.4 \mathrm{mmol})$ in the synthesis of $\mathrm{EV}$ and propyl iodide $\left(\mathrm{C}_{3} \mathrm{H}_{7} \mathrm{I}\right)(.42 \mathrm{~mL}, .75 \mathrm{~g}, 4.4$ mmol) in the synthesis of PV, were combined with 4,4'-bipyridine $\left(\mathrm{C}_{10} \mathrm{H}_{8} \mathrm{~N}_{2}\right)(\mathrm{EV}: .3345 \mathrm{~g}, 2.142$ mmol; PV: $.3332 \mathrm{~g}, 2.133 \mathrm{mmol}$ ) in a $100 \mathrm{~mL}$ round-bottom flask. The reactants were dissolved 
in $20 \mathrm{~mL}$ of acetonitrile, stirred, and heated to reflux for 24 hours. The solution was cooled, and the solid product, an orange powder (EV) or a dark red powder (PV), was filtered and washed with ethyl acetate. $^{22}$ Purity was confirmed by powder X-ray diffraction (PXRD) as compared to simulated patterns from single crystal diffraction analysis (Figures S2 and S3).

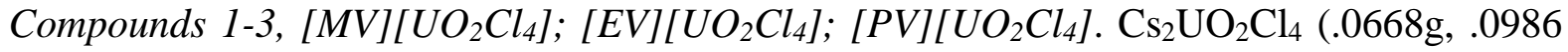
$\mathrm{mmol}$;.0677 g, .999mmol; .0679 g, .100mmol for 1-3 respectively) was combined with the corresponding viologen-halide salt: (1) methyl viologen dichloride hydrate $\left(\mathrm{C}_{12} \mathrm{H}_{14} \mathrm{~N}_{2} \mathrm{Cl}_{2} \cdot \mathrm{H}_{2} \mathrm{O}\right)$ (.102mmol, .0263g); (2) ethyl viologen diiodide $\left(\mathrm{C}_{14} \mathrm{H}_{18} \mathrm{~N}_{2} \mathrm{I}_{2}\right)$ (.103 mmol, .0482 g); (3) propyl viologen diiodide $\left(\mathrm{C}_{16} \mathrm{H}_{22} \mathrm{~N}_{2} \mathrm{I}_{2}\right)(.102 \mathrm{mmol}, .0505 \mathrm{~g})$, and dissolved in water. Slow evaporation of the solution yielded yellow block crystals (1 and 2) and dark-yellow shard-like crystals (3) after 10 days. PXRD patterns of bulk samples were compared to calculated patterns, based on SCXRD data of 1-3, to verify the product purity (Figures S4-S6). Crystals were physically separated and harvested for further analysis.

X-ray Crystallography. Crystals of sufficient quality were collected from each corresponding reaction and mounted on MiTeGen micromounts. X-ray diffraction data was collected, at $100 \mathrm{~K}$ on a Bruker D8 Quest equipped with an Incoatec I $\mu$ S 3.0 Microfocus X-ray source (Mo K $\alpha$, $\lambda=0.71073 \AA$ ) and Photon II detector. ShelXT was used to determine molecular structure via intrinsic phasing methods through the APEX III software package. ${ }^{23}$ Further structural refinements were carried out using SHELXL-2014 in the program ShelXle. ${ }^{24}$ Hydrogen atoms were placed in idealized positions for aromatic, secondary, and primary carbons, respectively, and allowed to ride on their parent atoms. Further information on modelling and refinement can be found in the Supporting Information (SI). We note that $\mathbf{3}$ exhibited significant positional disorder of both the uranyl tetrachloride anion and the viologen molecule. The interatomic distances have been expressed as ranges of possible interaction lengths and errors associated with distances are omitted. Details of the disorder are included in the crystallographic information file of 3 .

Table 1: Crystal structure and refinement data for 1-3.

\begin{tabular}{llll}
\hline \multicolumn{1}{c}{$\mathbf{1}$} & \multicolumn{1}{c}{$\mathbf{2}$} & \multicolumn{1}{c}{$\mathbf{3}$} \\
\hline CCDC ref code & & & \\
Formula & {$\left[\mathrm{C}_{12} \mathrm{H}_{14} \mathrm{~N}_{2}\right]\left[\mathrm{UO}_{2} \mathrm{Cl}_{4}\right]$} & {$\left[\mathrm{C}_{14} \mathrm{H}_{18} \mathrm{~N}_{2}\right]\left[\mathrm{UO}_{2} \mathrm{Cl}_{4}\right]$} & {$\left[\mathrm{C}_{16} \mathrm{H}_{22} \mathrm{~N}_{2}\right]\left[\mathrm{UO}_{2} \mathrm{Cl}_{4}\right]$} \\
Formula Weight, $\mathrm{g}$ & 598.08 & 626.13 & 654.18 \\
Crystal System & Monoclinic & Triclinic & Orthorhombic \\
Space Group & $\mathrm{P} 2{ }_{1} / \mathrm{n}$ & $\mathrm{P} \overline{1}$ & Pnnm \\
a, $\AA$ & $6.8889(3)$ & $8.1393(8)$ & $8.7757(4)$ \\
b, $\AA$ & $10.9983(5)$ & $8.1541(8)$ & $13.8926(6)$
\end{tabular}




\begin{tabular}{llll}
$\mathrm{c}, \AA$ & $8.6929(8)$ & $8.5361(4)$ \\
$\alpha,^{\circ}$ & $11.1155(4)$ & $108.605(3)$ & 90 \\
$\beta,^{\circ}$ & 90 & $117.112(3)$ & 90 \\
$\gamma,^{\circ}$ & $90.3850(10)$ & $93.241(3)$ & 90 \\
Volume, $\AA^{3}$ & 90 & $472.55(8)$ & $1040.70(8)$ \\
$Z$ & $842.16(6)$ & 1 & 2 \\
radiation & 2 & $\operatorname{Mo~K\alpha }(0.71073 \AA)$ & Mo Ka $(0.71073 \AA)$ \\
Temp., K & Mo Ka $(0.71073 \AA)$ & $100(2)$ & $100(2)$ \\
$\mathrm{R}_{1}$ & $100(2)$ & 0.0118 & 0.0493 \\
$\mathrm{R}_{\text {int }}$ & 0.0143 & 0.0306 & 0.0405 \\
\hline
\end{tabular}

Powder X-ray Diffraction. PXRD data were collected on ground bulk samples using the Rigaku MiniFlex 6G Benchtop X-Ray Diffraction System in the SmartLab Studio II software suite. Patterns were collected with $\mathrm{Cu} K \alpha(\lambda=1.5406 \AA)$ radiation from samples mounted on zerobackground silicon sample holders. The data was subsequently processed with the Match! 3 software package. ${ }^{25}$

Optical Measurements. Diffuse reflectance spectra were collected using Mikropack DH2000-BAL deuterium and halogen lamps generating light that was delivered and collected with a fiber-optic cable. An Ocean Optics Flame detector was used to analyze the scattered light. Spectra were collected on samples of 1-3 at $298 \mathrm{~K}$ while resting on $\mathrm{BaSO}_{4}$ pressed pellet, which served as a reference material. Data were processed using OceanView spectroscopy software and Tauc plots of reflection data were generated. Steady-state luminescence scans of 1-3 were collected at $298 \mathrm{~K}$ with a Fluorolog®-3 photoluminescence spectrophotometer from Horiba using a $450 \mathrm{~W}$ xenon arc lamp combined with a double excitation monochromator and double emission monochromator. A photomultiplier tube at $950 \mathrm{~V}$ was used as the emission detector.

Kinetic Measurements. Kinetic data were obtained via monitoring luminescence emission spectra over time as samples were irradiated with UV-light. Irradiation was achieved using a 450 W xenon arc source and a double excitation monochromator. Excitation monochromators were fixed at $345 \mathrm{~nm}$ for $\mathbf{1}$ and $325 \mathrm{~nm}$ for $\mathbf{2}$ and $\mathbf{3}$ with $14 \mathrm{~nm}$ slit widths for the light apertures, to achieve sufficient irradiation. Emission spectra were measured at various time intervals using the maximum excitation values of $345 \mathrm{~nm}$ for 1 and $325 \mathrm{~nm}$ for 2 and 3. Emission intensity values were taken from the emission maximum at $525 \mathrm{~nm}$ for $\mathbf{1}$ and $524 \mathrm{~nm}$ for $\mathbf{2}$ and $\mathbf{3}$. Kinetic experiments on 1-3 were repeated three times with fresh material and the average of the data obtained. To compare kinetic data to a non-viologen-bearing system, three control experiments 
were performed on $\mathrm{Cs}_{2} \mathrm{UO}_{2} \mathrm{Cl}_{4}$ with excitation and emission wavelengths of $350 \mathrm{~nm}$ and $522 \mathrm{~nm}$, respectively.

Computational Methods. Density functional theory (DFT) and time-dependent density functional theory (TD-DFT) were used to calculate optimized structures and molecular orbital transitions from truncated models of 1-3 (Figure S7, SI). Calculations were performed in the Gaussian 16 software (Gaussian Inc.) ${ }^{26}$ using the B3LYP ${ }^{27,28}$ functional with the def2-TZVP basis set for all $\mathrm{Cl}$ atoms $^{29}$, the $6-311 \mathrm{G}(\mathrm{d}, \mathrm{p})$ basis set for all $\mathrm{C} / \mathrm{H} / \mathrm{N} / \mathrm{O}$ atoms ${ }^{30}$, and the scalar relativistic Stuttgart energy-consistent relativistic 32 valence electron pseudopotential and associated ECP60MWB_SEG valence basis set for U atoms. ${ }^{31-33}$ Isodensity representations of molecular orbitals were rendered using the Avogadro (v1.2.0) software, $^{34}$ and calculated ground state parameters and full molecular orbital diagrams can be found in the SI. Density of state (DOS) calculations were performed on 1-3 using periodic boundary conditions in Gaussian 16 on crystallographically determined unit cells. DOS calculations were carried out via the HSE06 ${ }^{35-40}$ method utilizing the Heyd-Scuseria-Ernzerhof (HSE) hybrid combined with Perdew, Burke, and Ernzerhof's (PBE) exchange and correlation functions as well as the above-mentioned basis sets. Total density of states (TDOS) and partial density of states (PDOS) data were extracted and analyzed using the Multiwfn program. ${ }^{41}$ The TDOS was delineated into select PDOS components consisting of the $\mathrm{U} s / p, d$, and $f$ shells, the viologen $\pi$ and $\pi^{*}$ ( $p$ shell) molecular orbitals, and the halide $p$ shell.

\section{Results and Discussion.}

Local Structure. The $\left[\mathrm{UO}_{2} \mathrm{Cl}_{4}\right]^{2-}$ anion is common to 1-3 and features a central square bipyramidal uranyl cation coordinated equatorially by four chloride ligands (Figure 1). The average $\mathrm{U}=\mathrm{O}$ length is $1.76 \AA$ whereas the average $\mathrm{U}-\mathrm{Cl}$ bond is $2.67 \AA$ with no appreciable differences between uranyl anions in $\mathbf{1 - 3}$, whose complete crystallographic parameters are in Tables S1-S3. 


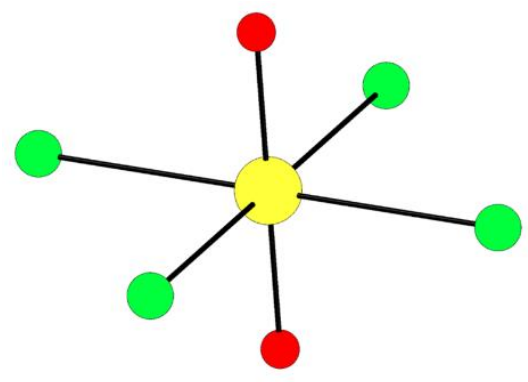

Figure 1: Ball and stick representation of the tetrachloro uranyl dianion showing the U(VI) (yellow) center coordinated axially to two $\mathrm{O}$ (red) ligands and equatorially to four $\mathrm{Cl}$ (green) ligands.

\section{Crystal Structure Descriptions.}

Compound 1, $\left(\mathrm{C}_{12} \mathrm{H}_{14} \mathrm{~N}_{2}\right)\left(\mathrm{UO}_{2} \mathrm{Cl}_{4}\right)$, crystalizes in the monoclinic space group, $\mathrm{P} 2_{1} / \mathrm{n}$, where both the uranyl anion and viologen cation lie on centers of inversion (Figure 2). This bimolecular salt is assembled in large part by simple anion-cation attractive forces, yet with a modicum of noncovalent interactions (NCIs), which may facilitate charge transfer (below). These include halogen $\cdots \pi$ and oxо $\cdots \pi$ interactions (lone-pair $\cdots \pi$ interactions), characterized by the overlap of the van der Waals $(\mathrm{vdW})$ radii of an electron rich atom $(\mathrm{Cl} / \mathrm{O})$ and an atom from an aromatic ring $(\mathrm{C} / \mathrm{N})$, and the lone pair donor species being positioned nearly perpendicular to the face of the ring. ${ }^{42}$ Of these, there are one halogen $\cdots \pi$, and one oxo $\cdots \pi$ interaction with ligand-to-ring distances of 3.382(3) $\AA(\mathrm{Cl} 1 \cdots \mathrm{C} 5), 3.007(3) \AA(\mathrm{O} 1 \cdots \mathrm{N} 1)$, and 3.019(3) $\AA$ (O1‥C1). These distances represent 98\%, 98\%, and 94\% of the vdW radii sum, respectively. Packing of 1 (Figure 2) shows the packing and relevant $\mathrm{NCIs}$ between the $\left[\mathrm{UO}_{2} \mathrm{Cl}_{4}\right]^{2-}$ anions and neighboring $\mathrm{MV}^{2+}$ cations.

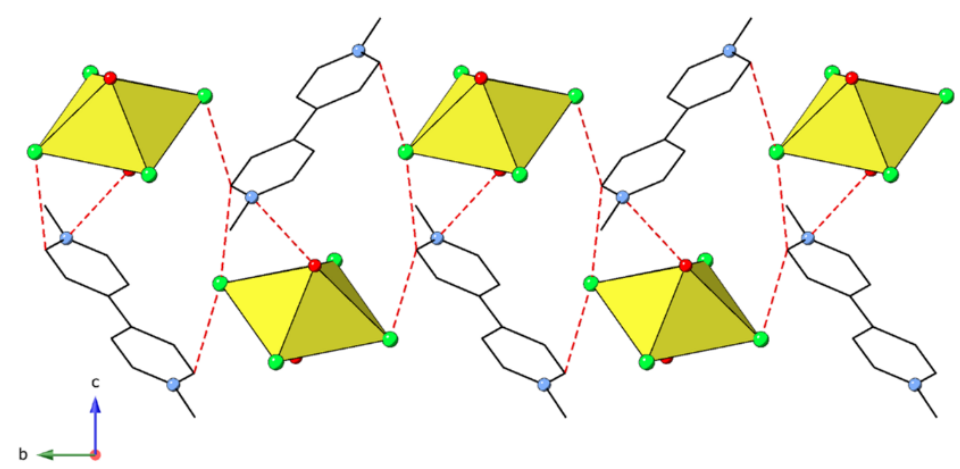

Figure 2: Polyhedral representation of the assembly of compound 1. Non-covalent interactions are highlighted by red dashed lines. Uranium metal centers are represented by yellow polyhedra. Color scheme: N, blue; O, red; green, $\mathrm{Cl}$. Hydrogen atoms have been omitted for clarity. 
Compound 2, $\left(\mathrm{C}_{14} \mathrm{H}_{18} \mathrm{~N}_{2}\right)\left(\mathrm{UO}_{2} \mathrm{Cl}_{4}\right)$, crystalizes in the triclinic space group P1. Like 1, the interactions between molecules in $\mathbf{2}$ are largely electrostatic (Figure 3). While short contacts between uranyl ligands and the aromatic viologen atoms are observed $(\mathrm{Cl} \cdots \mathrm{C} / \mathrm{N})$, no contact has the appropriate orientation, as described above, to be considered a halogen/oxo $\cdots \pi$ interaction. The molecular units assemble in alternating sheets of $\left[\mathrm{UO}_{2} \mathrm{Cl}_{4}\right]^{2-}$ anions in the (010) planes and the viologen cations composing the (020) planes (Figure 3).

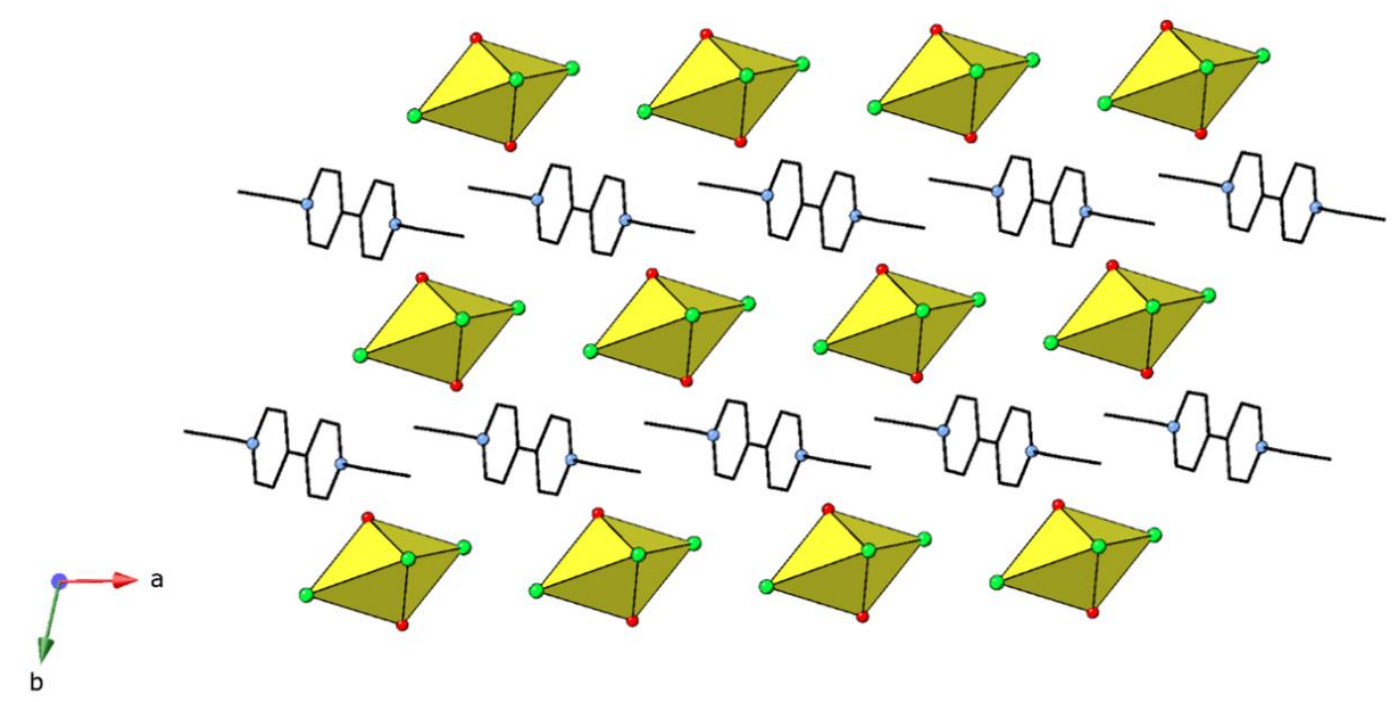

Figure 3: Polyhedral representation of the crystal packing in compound 2, shown along the $c$-axis.

Compound 3, $\left(\mathrm{C}_{16} \mathrm{H}_{22} \mathrm{~N}_{2}\right)\left(\mathrm{UO}_{2} \mathrm{Cl}_{4}\right)$, crystalizes in the orthorhombic space group Pnnm. Figure 4 shows the assembly of this compound which features a single NCI of note, a halogen $\cdots \pi$ interaction between a chloride ligand and the $\pi$-system of a neighboring viologen. This interaction has a range of possible distances and angles ( $3.448 \AA$ to $3.493 \AA$ ( $\mathrm{Cl}$ to $\pi$-centroid distance); $99.80^{\circ}$ to $102.03^{\circ}(\angle \mathrm{C}$-centroid-Cl)), owing to positional disorder in the modelling, but at its nearest occurrence of $3.448 \AA$, qualifies as a halogen $\cdots \pi$ interaction, albeit quite weak. ${ }^{42}\left[\mathrm{UO}_{2} \mathrm{Cl}_{4}\right]^{2-}$ units are flanked, along the $b$-axis, by propyl viologen cations that accommodate the lone $\mathrm{Cl} \cdots \pi \mathrm{NCI}$. This alternating anion-cation motif creates nearly discrete 2D sheets along the (001) plane. 


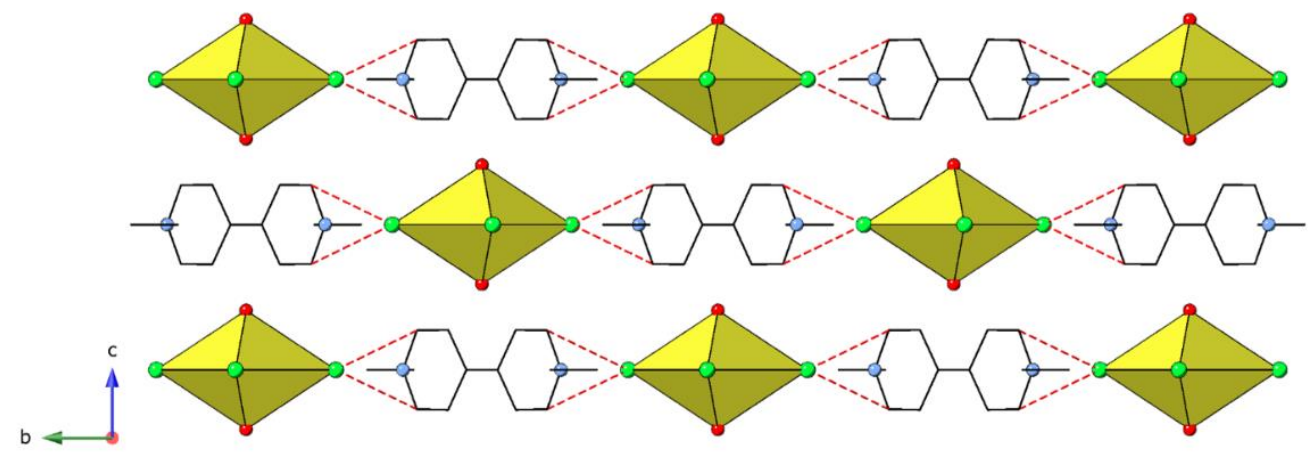

Figure 4: Polyhedral representation of the crystal packing in compound 3, shown along the $a$-axis. Halogen $\cdots \pi$ interactions are highlighted by red dashed lines.

Optical Properties. Solid-state diffuse reflectance spectra were collected at room temperature on compounds 1-3 (Figure 5). The reflectance profiles, in all cases, feature a strong, broad absorption band in the UV which extends into the visible region. The optical absorption edge decreases with cation size on the order of $\mathbf{1}>\mathbf{2}>\mathbf{3}$ at $2.44 \mathrm{eV}, 2.18 \mathrm{eV}$, and $2.09 \mathrm{eV}$, respectively (Figure S8). The absorption edge value is surmised to be dependent on the viologen species, owing to the common uranyl species in each compound, and would comport with typical viologen behavior where larger or weaker electron donating substituents tend to lead to smaller band gap energies. ${ }^{43}$ It is worth noting that the known uranyl tetrachloride absorption bands centered around $320 \mathrm{~nm}(3.87 \mathrm{eV})$ and $420 \mathrm{~nm}(2.95 \mathrm{eV})$ overlap with those of the viologen cations, demonstrating that the lower lying filled orbitals of the ion pairs are similar in energy.

The excitation and emission spectra (Figure 5) show typical uranyl luminescence features across 1-3. The excitation profiles of the materials show two broad excitation peaks centered at $345 \mathrm{~nm}$ and $420 \mathrm{~nm}$ corresponding to the ligand to metal charge transfer (LMCT) bands associated with the equatorial chlorides and axial oxygens, respectively. Specifically, these bands arise owing to the electronic transition from the ground state uranyl bonding orbitals $\left(3 \sigma_{\mathrm{u}}, 3 \sigma_{\mathrm{g}}, 1 \pi_{\mathrm{g}}, 2 \pi_{\mathrm{u}}\right)$ to non-bonding uranium $5 f \delta_{\mathrm{u}}$ and $\phi_{\mathrm{u}}$ orbitals. ${ }^{44}$ The finger-like peaks observed in the emission profile, like those in the excitation spectra, result from vibronic coupling to the symmetric $\mathrm{U}=\mathrm{O}$ stretch. Notably, compounds $\mathbf{2}, \mathbf{3}$, and to a lesser extent $\mathbf{1}$, display additional vibronic features in the emission band, which corresponds to coupled U-Cl vibrational modes (a phenomena we have reported previously for other uranyl tetrachloride containing materials). ${ }^{12}$ There are notable differences in the excitation profiles across 1-3 (Figure 5, right), namely, the excitation bands vary in relative intensities as the identity of the viologen changes. For example, in $\mathbf{1}$ the axial and equatorial excitation bands are similar in intensity whereas for $\mathbf{3}$ the equatorial excitation band is 
much higher in intensity than the axial band. A reduction in relative band intensity of the low energy axial band is indicative of more efficient equatorial ligand charge transfer resulting in emission (as opposed to nonradiative decay). This phenomenon is more pronounced in the compounds with larger viologen substituents, though the reason for this trend is not clear.
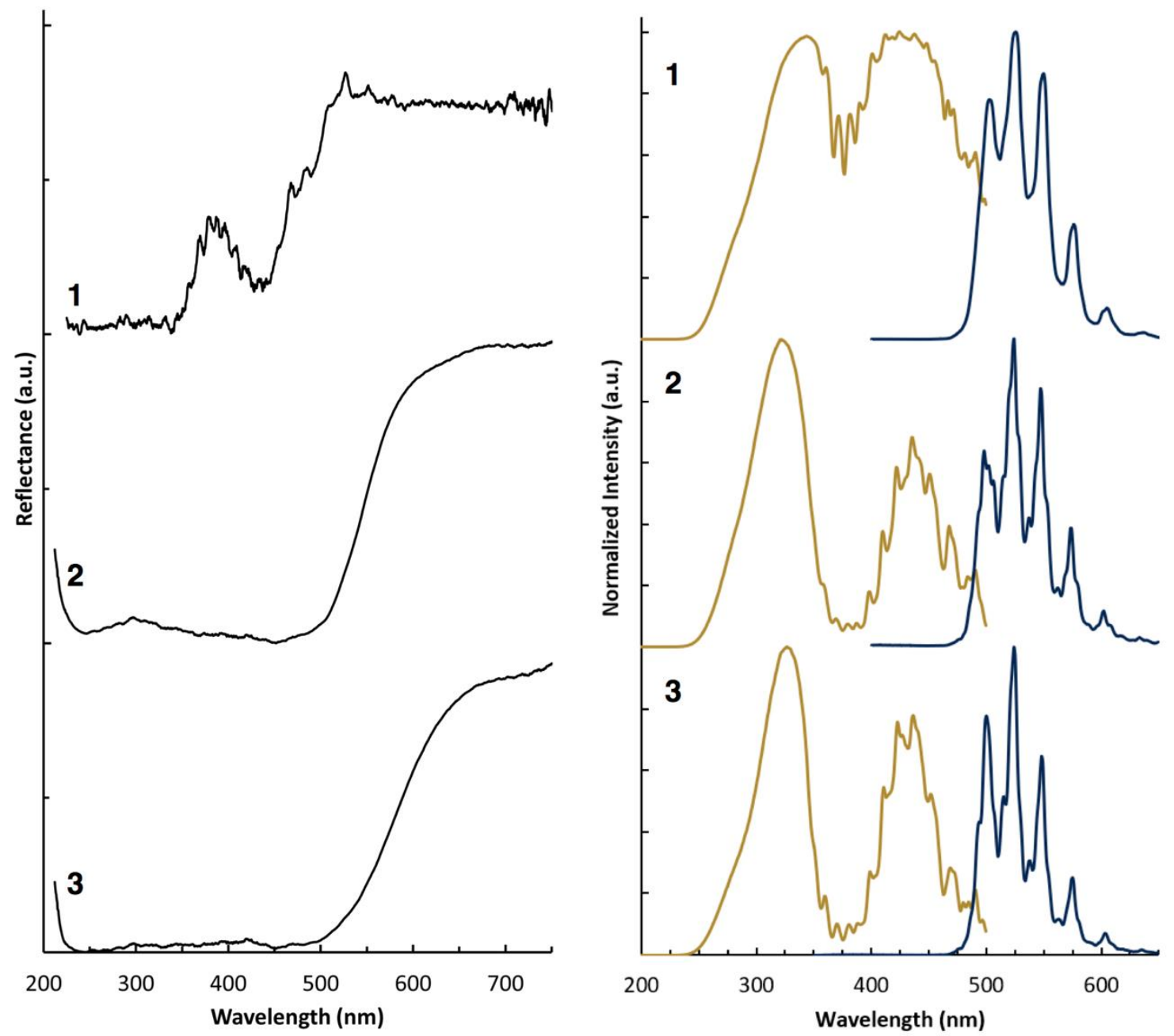

Figure 5: Diffuse reflectance (left) and photoluminescence (right) spectra of compounds 1-3 at $298 \mathrm{~K}$. Excitation spectra are shown in gold and emission spectra are shown in blue. The size of the viologen species $(\mathbf{3}>\mathbf{2}>\mathbf{1})$ corresponds to a greater relative intensity of the high-energy excitation band $(\sim 335 \mathrm{~nm})$, indicating that the charge transfer in the chloride ligand, relative to that of the oxygen, occurs to a greater extent in the emissive species as viologen size increases.

\section{Kinetics.}

At the beginning of this study of pairing the uranyl tetrachloride anion with various viologens, it was unclear how the latter would influence the optical properties of the uranyl species. During the course of luminescence characterization, however, it became clear that the high-energy excitation band (the most intense band in compounds 1-3), began red shifting as spectrum 
acquisition time increased. This was observed in addition to a discernible decrease in overall emission intensity. Probing these observations further indicated that the luminescence profiles of the materials were changing, the degree to which was influenced by the amount of time the sample was irradiated. These observations, which from our perspective were not anticipated features of uranyl tetrachloride containing materials, prompted a deeper and more systematic experimental inquiry, as well as a computational effort to rationalize the observed behavior.

Exposure of 1-3 to UV light $(\sim 350 \mathrm{~nm})$ leads to the gradual quenching of uranyl emission intensity over time. This phenomenon was investigated by measuring the emission and excitation of 1-3 at 5 to 30 min intervals over the course of 3 hours of UV irradiation (Figure 6), and it was observed that the overall intensity reduction occurs on the order of $\mathbf{1}>\mathbf{2}>\mathbf{3}$ at $53 \%, 67 \%$, and $84 \%$, respectively. The excitation spectra reflect the loss of intensity of the emission; however, we note a difference in the relative reduction of the axial and equatorial bands. The equatorial charge transfer excitation band $(250 \mathrm{~nm}-350 \mathrm{~nm})$ undergoes red-shifting and is dramatically reduced relative to the axial charge transfer excitation band $(400 \mathrm{~nm}-475 \mathrm{~nm})$. This is most obvious in $\mathbf{3}$, where the axial band intensity is reduced by $\sim 33 \%$ and the equatorial is reduced by $\sim 70 \%$. Interestingly, the emission quenching was partially reversed by allowing the sample to remain in a dark environment overnight, and after 20 hours, a notable portion of the luminescence intensity was recovered in all samples (7-21\% recovery of max emission intensity; Figure S9, SI). 

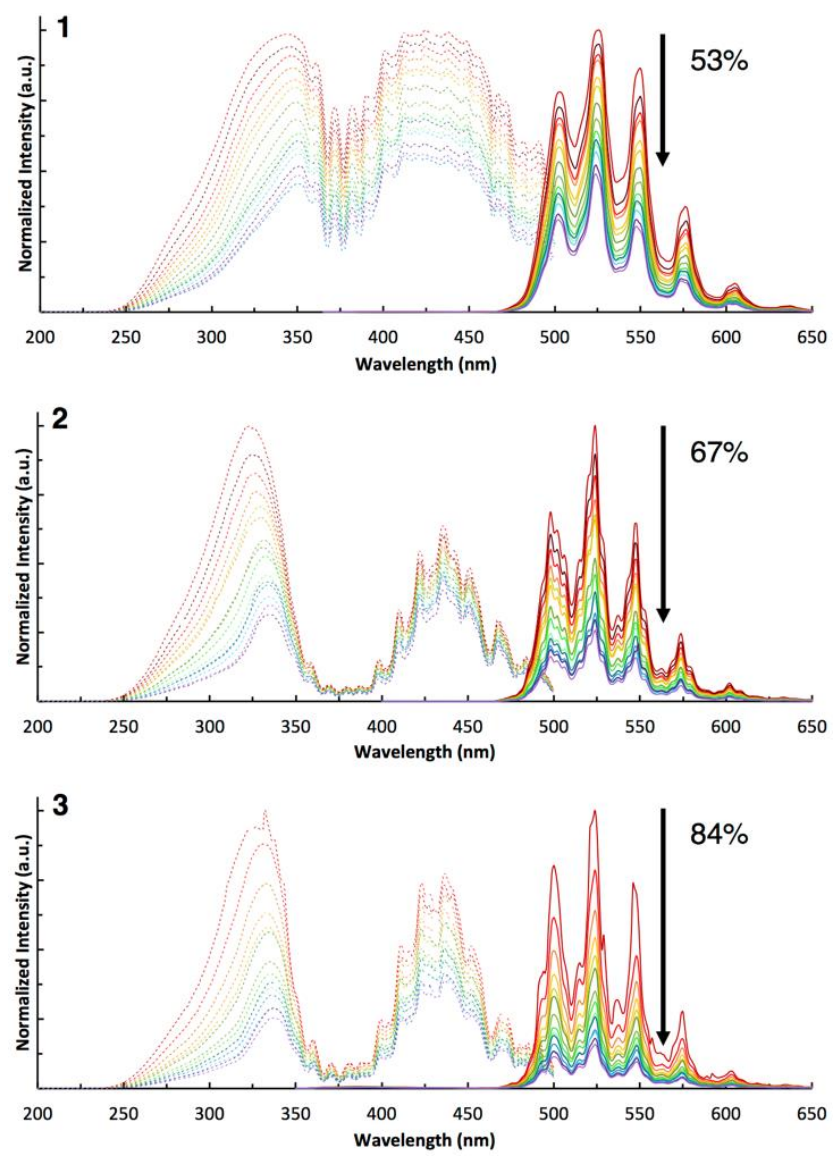

Figure 6: Luminescence spectra of 1-3 collected over 3 hours at different time intervals following exposure to UV-light. This shows that emission intensity is quenched as a function of UV light exposure.

The rate of emission quenching decreases significantly after 2 hours of exposure with no further quenching after 3 hours. Time-dependent emission quenching of 1-3 obeys second-order reaction kinetics: $1 /\left[\left(I_{\mathrm{t}}-I_{\infty}\right) /\left(I_{0}-I_{\infty}\right)\right]-1 /\left(I_{0}-I_{\infty}\right)=k t$, where $k$ is the second-order rate constant and $I_{0}$, $I_{\mathrm{t}}, I_{\infty}$ are the intensity values at time zero, time $\mathrm{t}$, and the equilibrium point, respectively. This is consistent with the bimolecular process of electron transfer between molecular units, including in viologen containing materials. ${ }^{45-47} \mathrm{We}$ have plotted this relationship in Figure 7 and determined the rate constants of 1-3 to be $0.0458 \mathrm{~mol}^{-1} \mathrm{~min}^{-1}, 0.0461 \mathrm{~mol}^{-1} \mathrm{~min}^{-1}$, and $0.076 \mathrm{~mol}^{-1} \mathrm{~min}^{-1}$, respectively. It is clear that $\mathbf{3}$ experiences the most rapid quenching, while $\mathbf{1}$ and $\mathbf{2}$ are much slower with equivalent rates. Given the similarity of the uranyl anions in 1-3, we attribute the difference in rates to the viologen species. It has long been known that the viologen substituent is responsible for changes in the reduction potential of these dicationic units where larger or more electron donating groups give rise to larger potential values. ${ }^{48}$ Plotting of the second order rate constant versus the viologen reduction potential (Figure S10, SI) yields a linear relationship, indicating that 
the reaction rate is dependent on the viologen species and independent of the uranyl unit. As the luminescence arises from the uranyl anion, its loss of intensity over time signifies the gradual conversion of the $\left[\mathrm{UO}_{2} \mathrm{Cl}_{4}\right]^{2-}$ unit into a relatively non-luminescent species. We therefore posit, and support below, that this occurs via photoinduced electron transfer between inorganic and organic units whose reaction rate is a function of viologen identity. Such a mechanism is intriguing as it implies the presence of a relatively air stable oxidized $\left[\mathrm{UO}_{2} \mathrm{Cl}_{4}\right]^{\mathrm{n}-}(\mathrm{n}=0$ or 1) species.
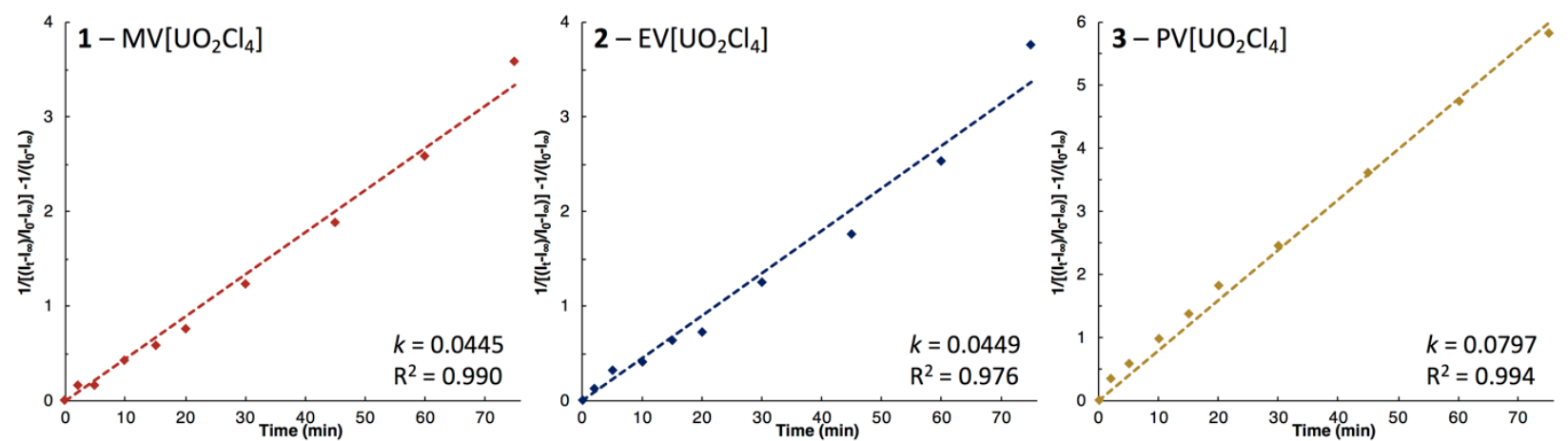

Figure 7: Kinetics of photoinduced emission quenching of 1-3. Emission monitored at $526 \mathrm{~nm}$ for $\mathbf{1}, 524 \mathrm{~nm}$ for $\mathbf{2}$, and $525 \mathrm{~nm}$ for 3 .

These observations highlighted the need for a control experiment to properly attribute the observed photoreactivity to the viologen-uranyl tetrachloride ion pair, and not strictly the uranyl species alone. As such $\mathrm{Cs}_{2} \mathrm{UO}_{2} \mathrm{Cl}_{4}$ was irradiated in the same manner as that for 1-3 and displayed a noticeable loss of emissive intensity $(\sim 36 \%)$. This was surprising given that this is a well-studied complex and such photoreactivity, to our knowledge, has not previously been described. While at first it seemed a similar PET process may be at play in $\mathrm{Cs}_{2} \mathrm{UO}_{2} \mathrm{Cl}_{4}$ (as in 1-3), a few significant differences were observed that dispelled this notion. First, all of the lost emissive intensity was recovered ( $43 \%)$ after 20 hours in darkness in two of three experiments, and nearly all emission intensity returned in the third (Figure S11). This contrasts with the partial recovery observed in the viologen containing species (Figure S9). Second, the excitation profile experiences no significant band shifting, and the relative intensity of the bands remain constant regardless of irradiation time. Lastly, and of most importance, is that the rate of quenching follows a first-order rate law, which is inconsistent with the second-order law(s) observed in 1-3 (Figure S12).

Literature Precedence of Uranyl Photoreactivity. The photoreactivity of uranyl-bearing systems has long been observed and is frequently utilized in a variety of contexts. ${ }^{9,49-52}$ Typically, the process is related to the phenomena detailed by Espenson et. al., whereby a uranyl ion in 
solution is excited by incident light to form a highly oxidizing $\mathrm{UO}_{2}{ }^{2+*}$ species. ${ }^{2}$ This species, in turn, reacts with organic substrates or water, usually via hydrogen abstraction, to create organic radicals and a newly reduced $\mathrm{U}(\mathrm{V}) \mathrm{O}_{2}{ }^{+}$species. $\mathrm{U}(\mathrm{VI}) \mathrm{O}_{2}{ }^{2+}$ is regenerated upon the oxidation of the pentavalent species, either by an organic substrate or molecular oxygen. In the latter case, oxygen can be converted to peroxide in solution which, as discussed above, can result in peroxide bound uranyl species. ${ }^{1}$ This is closely related to how the photoreactivity of uranyl heterocatalysts causes $\mathrm{C}-\mathrm{H}$ bond activation in some substrates. ${ }^{4}$ It has also recently been suggested that uranyl heterocatalytic MOFs, with substrate accessible void space can photoradicalize and stabilize pentavalent uranium in its structure. ${ }^{5} \mathrm{U}(\mathrm{V})$ does not emit the same characteristic $\mathrm{U}\left(\mathrm{VI} \mathrm{O}_{2}{ }^{2+}\right.$ luminescence signature, as such, we needed to employ due diligence in assessing possible formation of a pentavalent species.

Probing for $\mathbf{U}(\mathbf{V})$. Experimentally, we find no evidence that reduction of the uranium metal is taking place (through Raman, SCXRD, and luminescence). In the Raman spectra of uranylbearing materials it is common to observe a red-shift in the symmetric stretching peak of the uranyl unit (usually $\sim 850 \mathrm{~cm}^{-1}$ ) caused by a weakening in the $\mathrm{U}=\mathrm{O}$ bond as the non-bonding $5 f$ orbitals are populated upon formation of $U(V)$, however, after irradiation of 1-3 there is no change in the peak positions (Figures S13-S15). Relatedly, the $\mathrm{U}=\mathrm{O}$ bond weakening associated with U(V) formation tends to elongate the uranyl bond, but experimentally we find no significant differences between any bond lengths in fresh single crystal samples versus those that have been irradiated. In addition, the luminescence data suggest that while quenching of the uranyl unit is occurring, there is no evidence for the formation of $U(V)$, as we see that (i) there is no emergence of a $U(V)$ emission band (centered at $\sim 475 \mathrm{~nm})^{53}$ and (ii) the uranyl anion continues to emit characteristic U(VI) emission after the quenching has taken place (as evidenced by the diminishing equatorial excitation, seen in the excitation profile of 1-3; Figure 6). With regard to this latter point, it is worth noting that the red-shifting seen in the equatorial excitation band may be indicative of a destabilization of the $\mathrm{U}-\mathrm{Cl}$ bonding orbitals in the nominally quenched species. Moreover, the generation of $U(V)$ intermediates is hindered owing to: (i) the lack of free exchange of substrates as afforded by solution-state chemistry, (ii) the viologen is a reliable electron acceptor, making electron transfer to the uranium very unlikely.

Generation of Radical Species as a Means of Quenching. Having explored the role of the uranyl unit with regard to photoreactivity, we turn to the viologen species to probe its 
contributions. The presence of the viologen requires us to consider the unconventional possibility of electron transfer from the uranyl unit (electron rich) to the viologen (electron poor) ions, facilitated by incident UV light, which may initially be expressed by the equation

$$
\left[\mathrm{UO}_{2} \mathrm{Cl}_{4}\right]^{2-}+\mathrm{RV}^{2+} \rightarrow\left[\mathrm{UO}_{2} \mathrm{Cl}_{4}\right]^{\mathrm{n}-2}+\mathrm{RV}^{2-\mathrm{n}}
$$

where $\mathrm{RV}$ is a generic viologen species and $\mathrm{n}$ is the number of transferred electrons. This process would fit the well-documented electron accepting ability of viologen materials but requires uranyl tetrachloride anions to donate electrons.

Recent work that speaks to this possibility has been reported by Wang et al. and invokes the formation of ligand-based radicals, which disrupt the uranyl electronic transition pathway resulting in emission quenching over long periods of UV irradiation. ${ }^{7}$ Generally speaking, these compounds feature conjugated ancillary ligands that experience bond-breaking owing to incident radiation. Subsequent radicals are formed and stabilized by the bound ligands. If we consider an analogous process in 1-3, the radicalization would occur between the uranium center and a chloride ligand. This is reminiscent of the previously observed phenomena of equatorial ligand donors participating in LMCT, whereby an electron is transferred from the U-L bonding orbitals to the uranium $5 f$ orbitals upon excitation. ${ }^{54}$ The excited state would be stabilized by the unaffected chloride ligands in the equatorial plane, preventing the immediate reformation of $\mathrm{U}-\mathrm{Cl}$ bond and concurrent return to the ground state electron configuration. The result would be a radical shared amongst the equatorial ligands that disrupts the frontier orbital electron construct to such a degree that the emission pathway is no longer available and thus quenching occurs.

The main discrepancy between these systems that needs to be redressed is the stabilization of the radical: in the absence of extended conjugated ligands, is the radicalized chloride ligand sufficiently stabilized by the ligands of the uranyl tetrachloride complex to cause prolonged quenching? While the chloride ligands may at first seem less capable of charge distribution than large aromatic ligands, solution state studies have shown that chloride ions are capable of electron transfer to the excited state uranyl cation. ${ }^{55}$ This, paired with the fact that there are several chloride ligands with molecular bonding orbitals identical in energy to that of the radicalized chloride, leads us to believe that charge sharing throughout the equatorial ligand plane results in resonance stabilization of the excited state, and a perturbation of the electronic structure (U-Cl orbitals) such that further charge transfer (and emission) is less favorable. This may explain the observed 
quenching in the $\mathrm{Cs}_{2} \mathrm{UO}_{2} \mathrm{Cl}_{4}$ control experiment, and why the $\mathrm{U}-\mathrm{Cl}$ orbitals are destabilized with increasing irradiation (evidenced by the red-shifting of the high-energy equatorial LMCT band).

Photoinduced Electron Transfer Mechanism. Ikeda et al. also help us to predict what may happen to the excited electron, which resides in the uranium $5 f$ orbitals. In the solution state, and our control uranyl species, the excited electron has no pathway of relaxation besides returning to the radicalized chloride. However, in 1-3 we have reliable electron reservoirs neighboring the uranyl tetrachloride complex (i.e. the viologen) that could be capable of accepting the excited electron, thereby oxidizing the uranyl complex. This would explain the difference in rate with which emissive intensity returns to the $\mathrm{Cs}_{2} \mathrm{UO}_{2} \mathrm{Cl}_{4}$ versus the viologen-bearing materials, as well as the decline in the relative intensity of the high-energy equatorial excitation band (as the equatorial ligands are deprived of electrons). Moreover, it would also follow that if the viologen species were changed, the electron accepting capability or radical stability of the viologen would alter the rate of quenching.

Bearing this proposed photoreactivity mechanism in mind, we initially proposed a derivative of Wang's mechanism by the following elementary steps:

$$
\begin{array}{ll}
{\left[\mathrm{UO}_{2} \mathrm{Cl}_{4}\right]^{2-}+\mathrm{h} v \rightarrow *\left[\mathrm{UO}_{2} \mathrm{Cl}_{4}\right]^{2-}} & \text { Uranyl Excitation } \\
*\left[\mathrm{UO}_{2} \mathrm{Cl}_{4}\right]^{2-}+\mathrm{RV}^{2+} \rightarrow\left\{*\left[\mathrm{UO}_{2} \mathrm{Cl}_{4}\right]^{2-} \cdots \mathrm{RV}^{2+}\right\} & \text { Complexation } \\
\left\{*\left[\mathrm{UO}_{2} \mathrm{Cl}_{4}\right]^{2-} \ldots \mathrm{RV}^{2+}\right\} \rightarrow\left[\mathrm{UO}_{2} \mathrm{Cl}_{4}\right]^{1-}+\mathrm{RV}^{1+} & \text { Electron Transfer }
\end{array}
$$

Considering the mechanism, stepwise, from an electronic perspective, we have initial excitation of the uranyl unit from a singlet ground state to an excited triplet state. Worth noting is that this process is the product of charge transfer from bonding orbitals, mostly chloride ligand in character, to the uranium $5 f$ orbitals. ${ }^{44}$ Once promoted, the excited electron would be transferred to the vacant viologen $\pi^{*}$ orbital which would lead to an interaction between the excited uranyl unit and the viologen. Once the interaction ceases, the excited electron of the uranium (originally from the uranyl ligands) would be transferred to the viologen creating a new monocationic doublet viologen species and an oxidized monoanionic uranyl tetrachloride complex. The non-trivial process of formal electron transfer across molecular fragments would set this photochemical mechanism apart from those previously documented for radical-forming solid uranyl materials. 


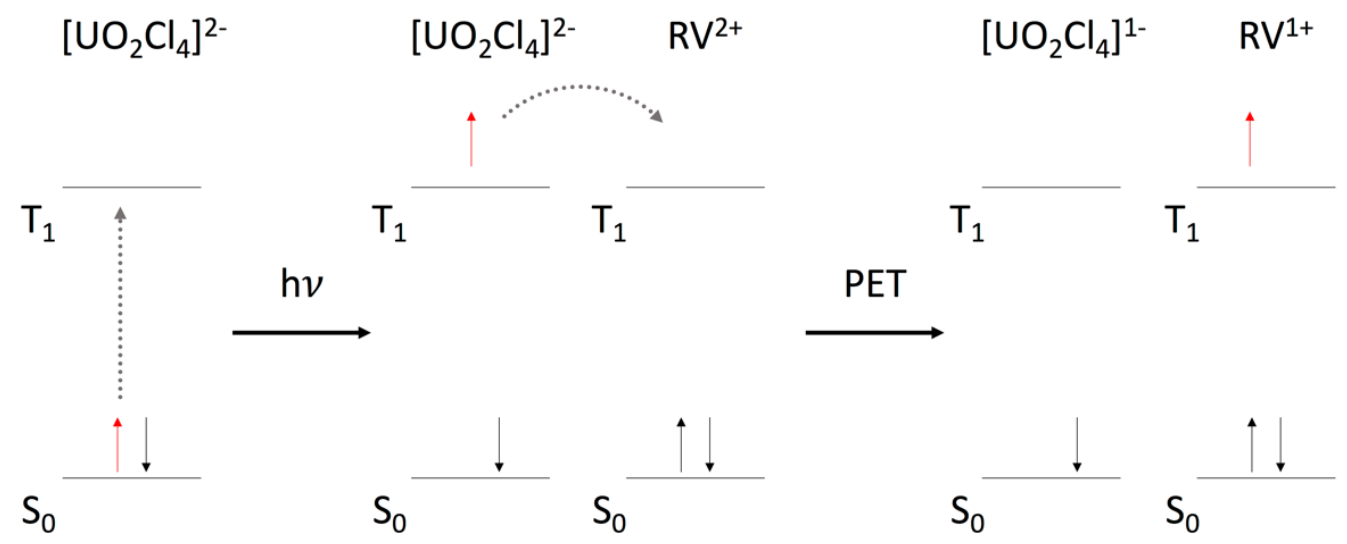

Figure 8: A simplified diagram describing the excitation and subsequent transfer of one electron from the uranyl species to the viologen molecule via photoelectron transfer. $\mathrm{S}_{0}$, singlet ground state; $\mathrm{S}_{1}$, first excited state; $\mathrm{T}_{1}$, first triplet state; PET, photoinduced electron transfer.

Criteria for Electron Transfer. For this process to be viable, the properties of the materials must satisfy certain conditions: (i) the process must be thermodynamically favorable and (ii) electronic structure and excited state transitions must serve as pathways to electron transfer. We probed these two criteria using a hybrid experimental and computational approach; experimentally, we employed the Rehm-Weller equation to determine thermodynamic likelihood based on the energy of light being absorbed by the material, and the reduction potentials of the relevant species. Computationally, density of state calculations allowed us to determine the band structure of the materials in order to evaluate whether or not an electronic structure that is amenable to electron transfer from the $\mathrm{U} 5 f$ orbitals to the viologen $\pi^{*}$ orbitals is present. We also carried out free-energy change and TD-DFT calculations to reinforce our experimental thermodynamic data and calculated the origin and destination of electronic transitions that would be relevant to electron transfer. With these data we validated the possibility of an oxidized uranyl tetrachloride species in these materials.

Rehm-Weller Analysis. In order to assess the thermodynamic favorability associated with electron transfer from uranyl tetrachloride to the corresponding viologen species, a Rehm-Weller analysis was conducted using the equation:

$$
\Delta \mathrm{G}_{\mathrm{ET}}=\left(\mathrm{E}_{\mathrm{ox}}-\mathrm{E}_{\mathrm{red}}\right)-\mathrm{E}_{\mathrm{s}}-\frac{\mathrm{e}_{\mathrm{s}}^{2}}{\varepsilon_{\mathrm{a}}}
$$

The Rehm-Weller equation describes the relationship between the reduction potentials of the redox pair involved in electron transfer $\left(E_{o x}, E_{r e d}\right)$, the ground state singlet energy of the complex $\left(E_{s}\right)$, 
and the subsequent coulombic attraction the pair experience as a result of the reaction $\left(\mathrm{e}_{\mathrm{o}}{ }^{2} / \varepsilon_{\mathrm{a}}=\right.$ $0.15 \mathrm{eV}) .{ }^{56}$ Standard reduction potentials of the viologen units have been reported previously at $0.446 \mathrm{~V},-0.449 \mathrm{~V}$, and $-0.635 \mathrm{~V}$ for methyl, ethyl, and propyl viologen, respectively. ${ }^{57,58}$ While an oxidation potential for $\left[\mathrm{UO}_{2} \mathrm{Cl}_{4}\right]^{2-}$ is unreported, we may instead use the potential associated with the oxidation of the chloride ligands $(-1.3583 \mathrm{~V})$ assuming no overall change in the oxidation state of the $\mathrm{UO}_{2}{ }^{2+}$ ion. ${ }^{59}$ The $\mathrm{E}_{\mathrm{s}}$ value are calculated based from the absorption edge of these materials, which are derived from the DRS spectra. Rehm-Weller parameters are provided in Table S4 (SI) with calculated $\Delta \mathrm{G}$ values of $-3.51 \mathrm{eV},-3.24 \mathrm{eV}$, and $-2.97 \mathrm{eV}$ for $\mathbf{1}, \mathbf{2}$, and $\mathbf{3}$, respectively. The analysis confirms that the photochemical reaction of a photoexcited electron transfer from the uranyl anion to the viologen cation has a negative $\Delta \mathrm{G}$ value in all cases, and thus is thermodynamically favorable. This analysis supports our reaction mechanism described above in that the uranyl unit acts as a photoexcited electron donor to generate a reduced viologen cation and oxidized uranyl tetrachloride ion.

Changes in Free Energy $\left(\Delta \mathrm{E} \mathrm{kJ} \mathrm{mol}^{-1}\right)$. As initially indicated by the Rehm-Weller analysis, the transfer of an electron from $\left[\mathrm{UO}_{2} \mathrm{Cl}_{4}\right]^{2-}$ to the viologen species occurs as a thermodynamically favorable reaction. To validate further, we have calculated the reaction energies of the $\left[\mathrm{UO}_{2} \mathrm{Cl}_{4}\right]^{2-}$ and viologen units in various oxidation states (Table S5). The change in energy from the singlet dianionic $\left[\mathrm{UO}_{2} \mathrm{Cl}_{4}\right]^{2-}$ to the triplet $\left[\mathrm{UO}_{2} \mathrm{Cl}_{4}\right]^{2-}$ or doublet $\left[\mathrm{UO}_{2} \mathrm{Cl}_{4}\right]^{1-}$ species is positive/endothermic for both charges/spins. The greatest change in energy $(+221 \mathrm{~kJ} / \mathrm{mol})$ occurs as the uranyl unit electronically rearranges from the singlet to triplet state. Notably, the doublet state or oxidized $\left[\mathrm{UO}_{2} \mathrm{Cl}_{4}\right]^{-}$species is lower in energy compared to triplet state (lower by $-40.3 \mathrm{~kJ} / \mathrm{mol}$ ), indicating the propensity to act as a potential metastable state upon oxidation. Corresponding changes in energy for the reduction of $\mathrm{RV}^{2+}$ to $\mathrm{RV}^{+}$are distinctly negative/exothermic and are greater in magnitude ( $852 \mathrm{~kJ} / \mathrm{mol}$ to $869 \mathrm{~kJ} / \mathrm{mol}$ ) compared to the uranyl species. The $\Delta \mathrm{E}$ for the reduction of the viologen species is on the order of $\mathrm{MV}^{2+}>\mathrm{EV}^{2+}>>\mathrm{PV}^{2+}$. Using the $\Delta \mathrm{E}$ values, we have calculated the free energy change of the reaction involving the redox of $\left[\mathrm{UO}_{2} \mathrm{Cl}_{4}\right]^{2-}$ and the viologen dication where the uranyl unit acts as an electron donor in Figure 9. Clearly the overall reaction is energetically favorable where the oxidized $\left[\mathrm{UO}_{2} \mathrm{Cl}_{4}\right]^{2-}$ and reduced $\mathrm{RV}^{+}$products are significantly lower in energy compared to the reactant species and the photoexcitation of the $\left[\mathrm{UO}_{2} \mathrm{Cl}_{4}\right]^{2-}$ triplet is the activation barrier. This change in free energy supports the Rehm-Weller assertion that the photoexcited triplet $\left[\mathrm{UO}_{2} \mathrm{Cl}_{4}\right]^{2-}$ is capable of transferring an electron to the 
viologen dication. Importantly, these calculations do not invoke a $\mathrm{U}(\mathrm{V})$ center and instead support the formation of a radicalized $\left[\mathrm{UO}_{2} \mathrm{Cl}_{4}\right]^{1-}$ species whereby the unpaired electron is delocalized across the $\mathrm{O} / \mathrm{Cl}$ ligands (Table S6, SI).

Free energy evaluation also requires considering the alternative reaction where the $\left[\mathrm{UO}_{2} \mathrm{Cl}_{4}\right]^{2-}$ acts as an electron acceptor and the viologen as an electron donor. Whereas the removal of an electron from the uranyl species has a $\Delta \mathrm{E}$ lower than that of the triplet state, the reduced $\left[\mathrm{UO}_{2} \mathrm{Cl}_{4}\right]^{3-}$ species (also a doublet) is significantly higher in energy than the triplet state (greater by +281 $\mathrm{kJ} / \mathrm{mol}$ ). Furthermore, oxidization of the viologen to produce a tricationic species is positive in energy and greater by an entire order of magnitude. The reaction coordinates demonstrate that this reaction, where the uranyl is the electron acceptor, is energetically unfavorable.
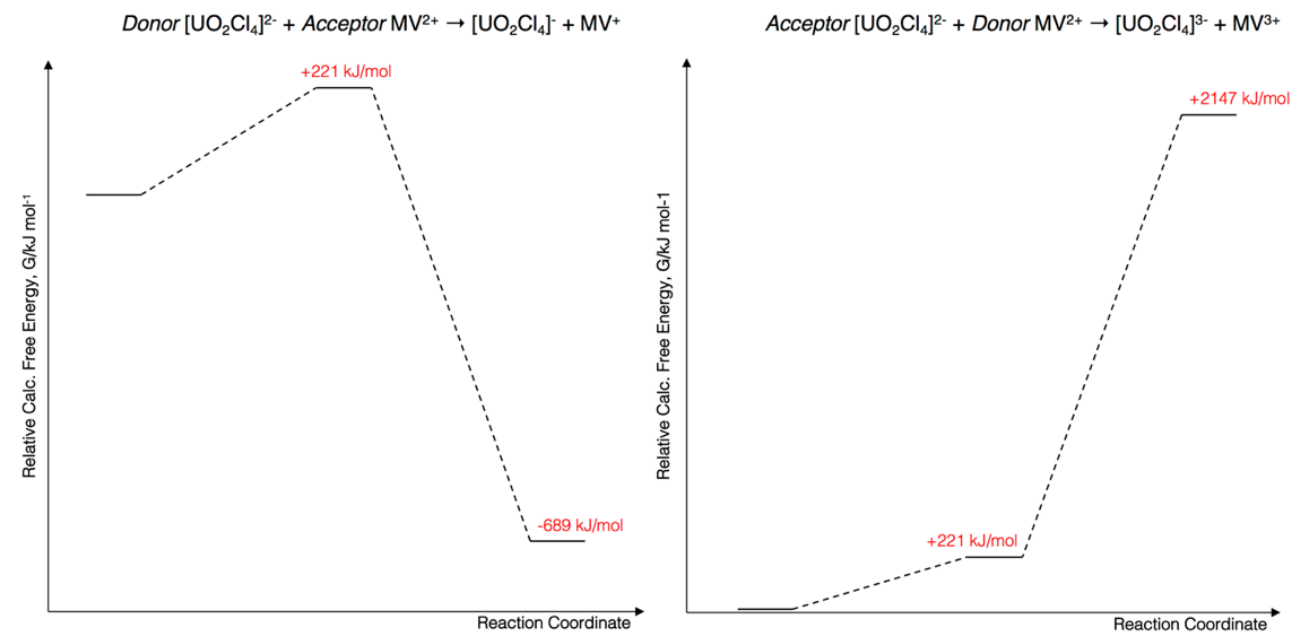

Figure 9: DFT calculated reaction coordinate diagram showing changes in free energy for the stepwise transfer of one electron between $\left[\mathrm{UO}_{2} \mathrm{Cl}_{4}\right]^{2-}$ and $\mathrm{MV}^{2+}$. The numbers listed above each energy level refer to the relative change in free energy in $\mathrm{kJ} \mathrm{mol}^{-1}$ versus the reactants.

Band Structure. Common to the reduction of viologens in photoreactive materials, and PET more generally, is the presence of energetically accessible $\pi^{*}$ molecular orbitals into the band structure, which may act as photoexcited electron acceptors. Excitation of the uranyl unit and subsequent capture of photoexcited electrons via viologen $\pi^{*}$ acceptors, as mentioned above, would constitute a formal electron charge-transfer mechanism between ion pairs. Ideally, for efficient electron transfer in this system, the $\pi^{*}$ acceptor orbitals should be energetically close to those of the $\mathrm{U} 5 f$ which serves as the lowest excited triplet state for the $*\left[\mathrm{UO}_{2} \mathrm{Cl}_{4}\right]^{2-}$ ion. To probe whether such conditions exist in these materials, we have mapped the band structure of 1-3 as well as $\left[\mathrm{UO}_{2} \mathrm{Cl}_{4}\right]^{2-}$ and the calculated total and partial density of states of $\mathbf{1 - 3}$ are shown in Figure 10. 


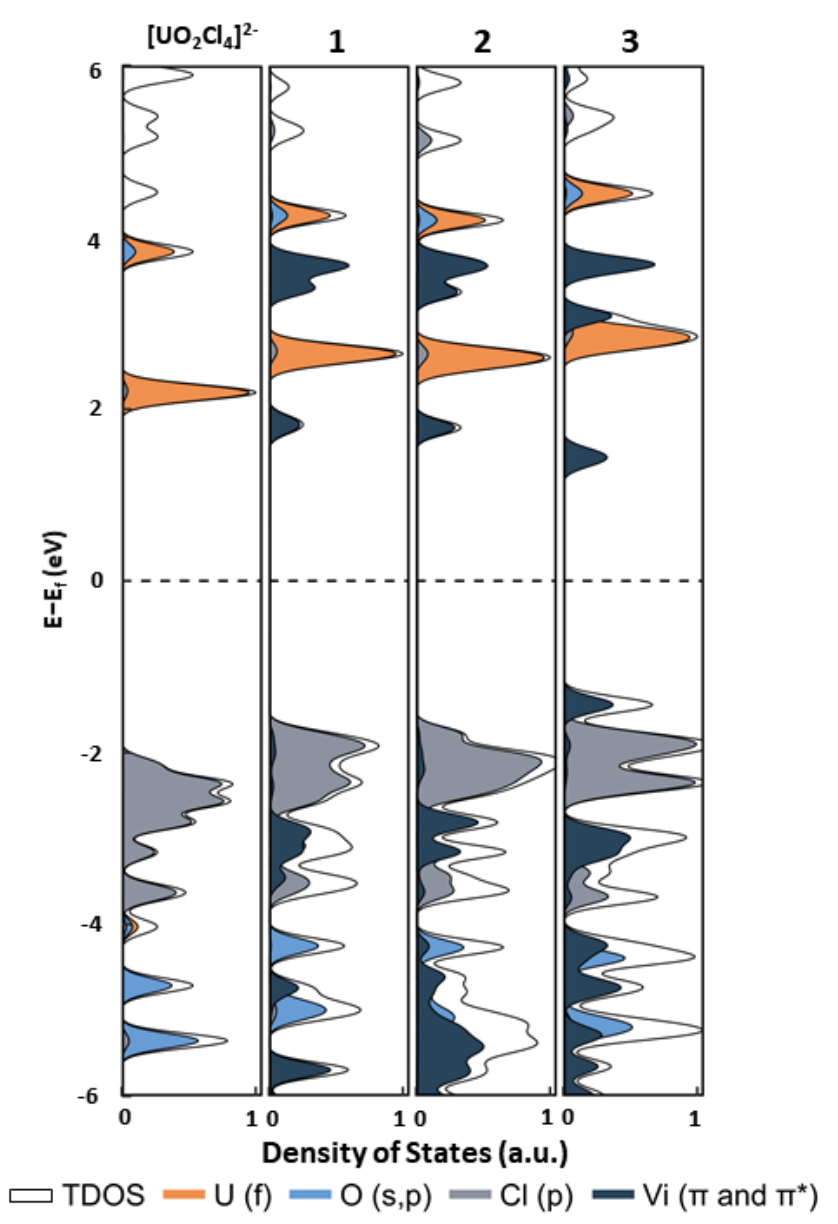

Figure 10: Total density of states of $\left[\mathrm{UO}_{2} \mathrm{Cl}_{4}\right]^{2-}$ and 1-3 and partial density of states projected onto atomic orbitals of $\mathrm{U}, \mathrm{O}$ and $\mathrm{Cl}$ atoms and molecular orbitals $\left(\pi\right.$ and $\left.\pi^{*}\right)$ of viologen cations. The conduction band of $\left[\mathrm{UO}_{2} \mathrm{Cl}_{4}\right]^{2-}$ (orange) is $\mathrm{U} 5 f$ in character, in agreement with Denning, but 1-3 each show that a viologen $\pi^{*}$ state (dark blue) has been introduced into the band structure. This new band is lower in energy than the U $5 f$ orbital and may allow for population of viologen $\pi^{*}$ orbitals by electrons from the uranyl tetrachloride anion. The Fermi level is shown as a dashed black line.

In the absence of viologen cations, the $\left[\mathrm{UO}_{2} \mathrm{Cl}_{4}\right]^{2-}$ valance band is composed of the $\mathrm{Cl} p$-states, whereas the conduction band is comprised of the empty $\mathrm{U} 5 \mathrm{f}$ atomic orbitals. This band structure is typical of uranyl containing compounds and has been documented previously. ${ }^{44}$ Introduction of viologen cations inserts $\pi^{*}$ molecular orbitals which, in terms of energy, lie below the $U$ ff. This orbital construct is consistent with isodensity renderings of the frontier orbitals (Figure 11), where the HOMO and HOMO-1 are dominantly $\mathrm{Cl} p$ in character with a minor $\mathrm{O} p$ contribution to the HOMO-1, while the LUMO and LUMO+1 are energetically degenerate $\pi^{*}$ orbitals that reside on the viologen cations. Such a band structure is ideal for formal electron transfer from the $\left[\mathrm{UO}_{2} \mathrm{Cl}_{4}\right]^{2-}$ 
anion to the viologen cations as population of the $\pi^{*}$ may act as the lowest possible triplet state. The $\pi^{*}$ energy decreases on the order of $\mathrm{MV}^{2+}>\mathrm{EV}^{2+}>\mathrm{PV}^{2+}$. The conduction band of 3 is of note as the filled $\pi$ orbitals of $\mathrm{PV}^{2+}$ are higher than the $\mathrm{Cl} p$-states of $\left[\mathrm{UO}_{2} \mathrm{Cl}_{4}\right]^{2-}$ making the frontier orbitals strictly viologen in origin.

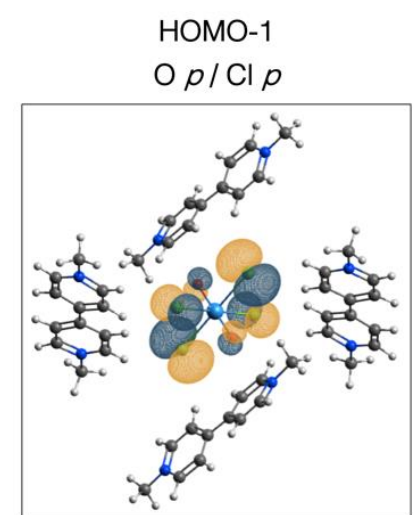

$-1.403 \mathrm{eV}$
$\mathrm{HOMO}$

$\mathrm{Cl} p$

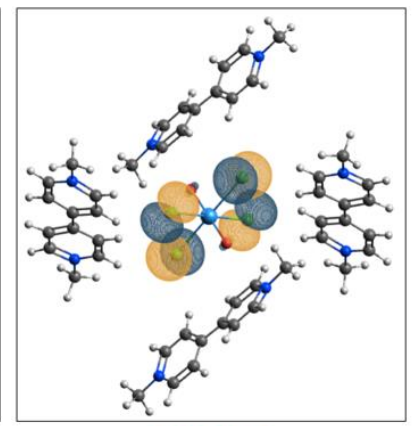

$-1.204 \mathrm{eV}$
LUMO

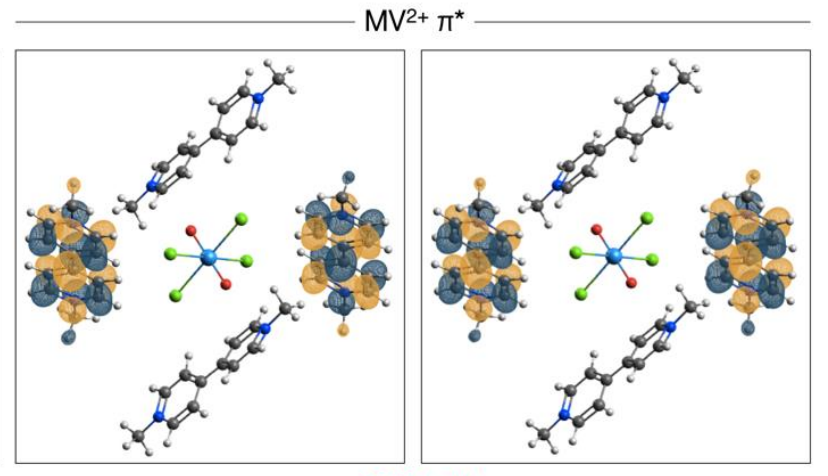

$1.204 \mathrm{eV}$
$\mathrm{LUMO}+1$

Figure 11: Isodensity representations of frontier molecular orbitals (HOMO-1 to LUMO+1) calculated for 1 . Orbital assignment provided above while energy levels are marked in red below. Note that the LUMO and LUMO+1 at $1.204 \mathrm{eV}$ are degenerate.

Calculated Electron Transitions. Time-dependent density functional theory calculations were carried out to ascertain the electronic transitions in 1-3 upon UV irradiation at the high energy (equatorial ligand) excitation band (345 for 1 or $325 \mathrm{~nm}$ for 2 and 3), and provide insight to the photochemical mechanism responsible for the loss of uranyl emission intensity. For compound 1, an energetically relevant singlet excited state is calculated at $359 \mathrm{~nm}$ with a strong oscillation value $(f=0.0187)$. Isodensity representations of the dominant molecular orbitals involved in this excited state transition are shown in Figure 12. Renderings of all molecular orbital transitions for this exited state are included in the SI. The dominant TD-DFT transitions at $359 \mathrm{~nm}$ for the singlet state can be described as a rearrangement of electrons about the $\left[\mathrm{UO}_{2} \mathrm{Cl}_{4}\right]^{2-}$ unit. Here, electrons originating from the $\mathrm{HOMO} / \mathrm{HOMO}-2$, which is a mixture of $\mathrm{O} p$ - and/or $\mathrm{Cl} p$-states, are populated into empty $\mathrm{U} 5 f$ atomic orbitals. As mentioned previously, this electronic behavior is typical of uranyl complexes, including uranyl tetrachloride. 


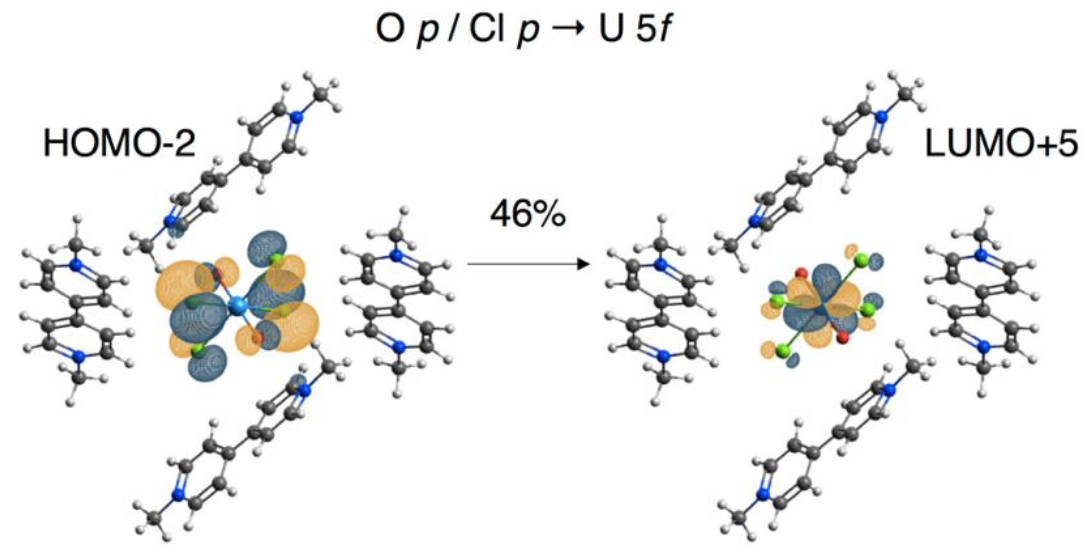

Figure 12: TD-DFT isodensity representations of dominant molecular orbitals in $\mathbf{1}$ involved in electronic transitions for the singlet state at $359 \mathrm{~nm}$. A total of $85 \%$ of the pathways are a $\mathrm{O} p / \mathrm{Cl}$ $p \rightarrow \mathrm{U} 5 f$ transition in nature.

Of interest is the TD-DFT analysis of the degenerate triplet states at $438 \mathrm{~nm}$, which corresponds to the experimental excitation peak at $436 \mathrm{~nm}$. Isodensity representations for orbital transitions at this energy are distinctly different from those of the previous singlet state. As shown in Figure 13, acceptor orbitals for the 438 triplet state are the LUMO +1 and LUMO +2 and are solely composed of the $\pi^{*}$ orbitals of the $\mathrm{MV}^{2+}$ cation. Importantly, this triplet state is lower in energy than that of the singlet state achieved via UV irradiation, and thus energetically accessible. The TD-DFT findings, while supporting the electron transfer between ion pairs, indicate two important points: (i) initial irradiation at $350 \mathrm{~nm}$ leads to a singlet $\mathrm{O} / \mathrm{Cl} p \rightarrow \mathrm{U} 5 f$ transition and (ii) this singlet state decays to a lower energy triplet state which resides on the $\mathrm{MV}^{2+}$, constituting an electron transfer from the excited state uranyl anion. TD-DFT analysis of compounds 2 and $\mathbf{3}$ provide nearly identical results, implying that this mechanism holds for all three uranyl viologen compounds.

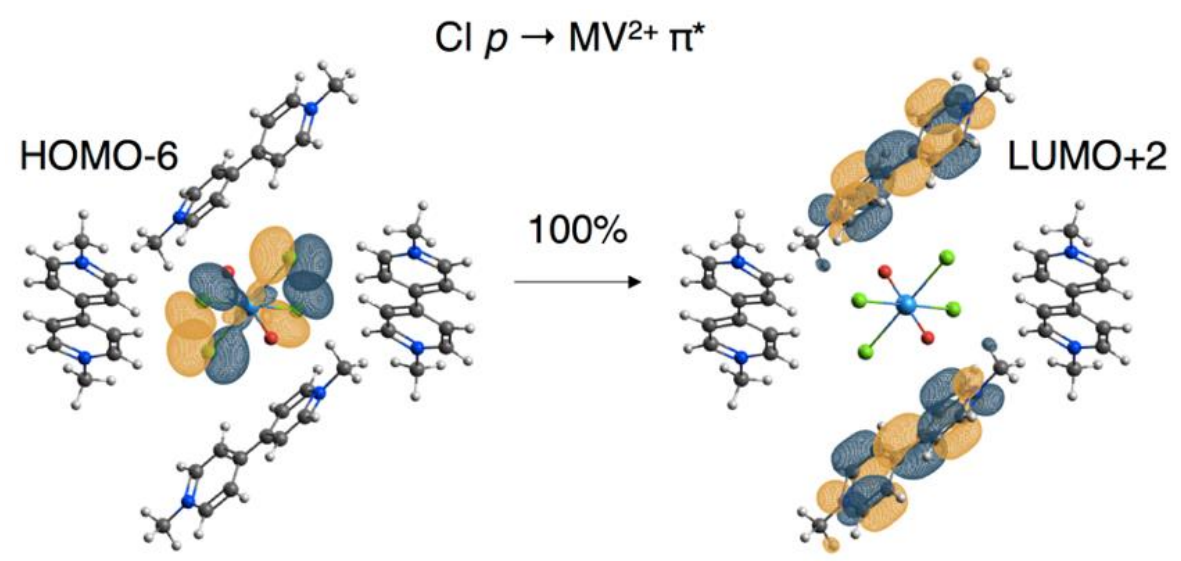

Figure 13: TD-DFT isodensity representations of molecular orbitals in $\mathbf{1}$ involved in electronic transitions for the triplet state at $438 \mathrm{~nm}$. This pathway is a $\mathrm{Cl} p \rightarrow \mathrm{U} 5 f$ transition. 


\section{Conclusion}

We describe the synthesis, characterization, and kinetic study of three novel uranylviologen-bearing materials, featuring uranyl tetrachloride and various alkylated viologens. Luminescence measurements reveal excitation and emission signatures characteristic of uranyl containing materials. Most notably, emission intensity is reduced when irradiated with UV light, indicating the possibility of a photoinduced electron transfer between ion pairs. Despite the popularity of the viologen as an agent for charge transfer, this presents the first systematic study of such a process occurring with the viologen in the presence of a uranyl molecular unit. A mechanism describing formal electron transfer from the uranyl tetrachloride unit to the viologen is detailed and supported by various experimental and computational analyses. The photoinduced reaction observed follows a $2^{\text {nd }}$ order rate law dependent on the viologen reduction potential and is consistent with known electron transfer mechanisms. Our hybrid experimental and computational approach clearly demonstrates the thermodynamic favorability and proper band structure and excitation pathways for the photoinduced oxidization of the $\left[\mathrm{UO}_{2} \mathrm{Cl}_{4}\right]^{2-}$ and subsequent reduction of the viologen ions.

To our knowledge, this is the first report of a photogenerated, solid-state, air stable uranyl tetrahalide radical. As such, our findings demonstrate a suitable methodology for the study of novel solid-state radical uranyl species with implications for $f$-orbital participation in bonding. Since this radicalization seems to persist over long periods of time, it provides the opportunity to investigate the effect this new activity has on the bonding and reactivity of these compounds. We may also investigate what role ligands play in the photoreactivity of solid-state uranyl materials considering the propensity of the uranyl ion to form several closely related anions (i.e. $\left[\mathrm{UO}_{2} \mathrm{Br}_{4}\right]^{2-}$, $\left[\mathrm{UO}_{2} \mathrm{SCN}_{5}\right]^{3-}$, etc.) as a platform for future study. Our findings have significant implications towards the study of uranyl chemistry writ large, including the use of the uranyl unit as a photocatalyst, and improving our fundamental understanding of the photochemical mechanisms afforded by its incorporation into new functional materials. Moreover, this may be a phenomenon that may possibly be repeated with other redox-active $f$-block elements which, in turn, may reveal novel information as to the bonding and reactivity of the transuranic elements.

\section{Associated Content}




\section{Supporting Information}

The Supporting Information is available free of charge on the ACS Publications website. Crystallographic information on CCDC 2118265-2118267 can be obtained free of charge by emailing data_request@ccdc. cam.ac.uk or by contacting The Cambridge Crystallographic Data Centre, 12 Union Road, Cambridge, CB2 1EZ UK; Fax +44(0)1223-336033; http://www.ccdc.cam.ac.uk/data_request/cif.

Description of crystallographic structures, Tauc plots, and additional NBO/NLMO calculations (PDF)

$\mathrm{X}$-ray data for compound $\mathbf{1}$ (CIF)

$\mathrm{X}$-ray data for compound 2 (CIF)

$\mathrm{X}$-ray data for compound $\mathbf{3}(\mathrm{CIF})$

\section{Author Information}

*Christopher L. Cahill - Department of Chemistry, The George Washington University, Washington, DC 20052, United States; orcid.org/0000-0002-2015-3595;

Email: cahill@gwu.edu

\section{Authors}

Jordan A. Herder - Department of Chemistry, The George Washington University, Washington, DC 20052, United States; orcid.org/ 0000-0003-2355-1457;

Email: herderja1@gwu.edu

Aaron D. Nicholas - Department of Chemistry, The George Washington University, Washington, DC 20052, United States; orcid.org/0000-0001-9003-2126;

Email: aaron_nicholas@gwu.edu

\section{Author Contributions}

The manuscript was written with contributions from all authors.

\section{Notes}

The authors declare no competing financial interests.

\section{Acknowledgment}

This work was performed at The George Washington University, and was funded by a DOE(0000257739). We thank Prof. Raymond J. Butcher (Howard University) for his assistance in the crystallographic modelling of our compounds and Prof. Karah Knope and Alexander Marwitz (Georgetown University) for use of Raman equipment.

\section{References}

(1) Thangavelu, S. G.; Cahill, C. L. Uranyl-Promoted Peroxide Generation: Synthesis and Characterization of Three Uranyl Peroxo $\left[\left(\mathrm{UO}_{2}\right)_{2}\left(\mathrm{O}_{2}\right)\right]$ Complexes. Inorganic Chemistry 2015, 54 (9), 4208-4221.

(2) Wang, W. D., Bakac, A., \& Espenson, J. H. Uranium(VI)-Catalyzed Photooxidation of Hydrocarbons with Molecular Oxygen. Inorganic Chemistry. 1995, 34 (24), 6034-6039. 
(3) McGrail, B. T.; Pianowski, L. S.; Burns, P. C. Photochemical Water Oxidation and Origin of Nonaqueous Uranyl Peroxide Complexes. Journal of the American Chemical Society 2014, 136 (13), 4797-4800.

(4) Wang, K. X.; Chen, J. S. Extended Structures and Physicochemical Properties of UranylOrganic Compounds. Accounts of Chemical Research 2011, 44 (7), 531-540.

(5) Zhang, X.; Li, P.; Krzyaniak, M.; Knapp, J.; Wasielewski, M. R.; Farha, O. K. Stabilization of Photocatalytically Active Uranyl Species in a Uranyl - Organic Framework for Heterogeneous Alkane Fluorination Driven by Visible Light. Inorganic Chemistry 2020, 59 (23).

(6) Liu, W.; Dai, X.; Xie, J.; Silver, M. A.; Zhang, D.; Wang, Y.; Cai, Y.; Diwu, J.; Wang, J.; Zhou, R.; Chai, Z.; Wang, S. Highly Sensitive Detection of UV Radiation Using a Uranium Coordination Polymer. ACS Applied Materials and Interfaces 2018, 10 (5), 4844-4850.

(7) Xie, J.; Wang, Y.; Liu, W.; Yin, X.; Chen, L.; Zou, Y.; Diwu, J.; Chai, Z.; AlbrechtSchmitt, T. E.; Liu, G.; Wang, S. Highly Sensitive Detection of Ionizing Radiations by a Photoluminescent Uranyl Organic Framework. Angewandte Chemie 2017, 129 (26), 7608-7612.

(8) Wang, Y.; Yin, X.; Liu, W.; Xie, J.; Chen, J.; Silver, M. A.; Sheng, D.; Chen, L.; Diwu, J.; Liu, N.; Chai, Z.; Albrecht-Schmitt, T. E.; Wang, S. Emergence of Uranium as a Distinct Metal Center for Building Intrinsic X-Ray Scintillators. Angewandte Chemie International Edition 2018, 57 (26), 7883-7887.

(9) Nieweg, J. A.; Lemma, K.; Trewyn, B. G.; Lin, V. S. Y.; Bakac, A. Mesoporous SilicaSupported Uranyl: Synthesis and Photoreactivity. Inorganic Chemistry 2005, 44 (16), 5641-5648.

(10) Andrews, M. B.; Cahill, C. L. Utilizing Hydrogen Bonds and Halogen-Halogen Interactions in the Design of Uranyl Hybrid Materials. Dalton Transactions 2012, 41 (14), 3911-3914.

(11) Deifel, N. P.; Cahill, C. L. The Uranyl Tetrachloride Anion as a Tecton in the Assembly of U(VI) Hybrid Materials. CrystEngComm 2009, 11 (12), 2739-2744.

(12) Surbella, R. G.; Andrews, M. B.; Cahill, C. L. Self-Assembly of $\left[\mathrm{UO}_{2} \mathrm{X}_{4}\right]^{2-}(\mathrm{X}=\mathrm{Cl}, \mathrm{Br})$ Dianions with $\gamma$ Substituted Pyridinium Cations: Structural Systematics and Fluorescence Properties. Journal of Solid State Chemistry 2016, 236, 257-271.

(13) Ashton, P. R.; Brown, C. L.; Chrysta1, E. J. T.; Goodnow, T.; Kaifer, A. E.; Parry, K. P.; Philp, D.; Slawin, A. M. Z.; Spencer, N.; Stoddarta, J. F.; Williamsd, D. J. The SelfAssembly of a Highly Ordered [2]Catenane. J. Chem. Soc., Chem. Commun. 1991, 9, 634639.

(14) Wang, Y.; Frasconi, M.; Stoddart, J. F. Introducing Stable Radicals into Molecular Machines. ACS Central Science 2017, 3 (9), 927-935.

(15) Li, H. Y.; Xu, J.; Li, L. K.; Du, X. S.; Li, F. A.; Xu, H.; Zang, S. Q. Photochromic Properties of a Series of Zinc(II)-Viologen Complexes with Structural Regulation by Anions. Crystal Growth and Design 2017, 17 (12), 6311-6319.

(16) Qiu, X. T.; Shi, Q.; Zhang, D. Q.; Lin, Q. F.; Sun, Y. Q. A Multi-Responsive CdViologen Complex: Photochromism, Photomodulated Fluorescence, and Luminescent Sensing. ChemistrySelect 2018, 3 (23), 6611-6616. 
(17) Li, M. H.; You, M. H.; Lin, M. J. Photochromism and Photomagnetism in Three CyanoBridged 3d-4f Heterobimetallic Viologen Frameworks. Dalton Transactions 2021, 50 (14), 4959-4966.

(18) Li, L. K.; Li, H. Y.; Li, T.; Quan, L. H.; Xu, J.; Li, F. A.; Zang, S. Q. Photochromic and Photomodulated Luminescence Properties of Two Metal-Viologen Complexes Constructed by a Tetracarboxylate-Anchored Bipyridinium-Based Ligand. CrystEngComm 2018, 20 (41), 6412-6419.

(19) Wang, Y.-W.; Li, M.-H.; Zhang, S.-Q.; Fang, X.; Lin, M.-J. Photochromic and Photocontrolled Luminescent Rare-Earth D-A Hybrid Crystals Based on Rigid Viologen Acceptors. CrystEngComm 2021, 23 (36), 6267-6275.

(20) Zeng, L. W.; Hu, K. Q.; Mei, L.; Li, F. Z.; Huang, Z. W.; An, S. W.; Chai, Z. F.; Shi, W. Q. Structural Diversity of Bipyridinium-Based Uranyl Coordination Polymers: Synthesis, Characterization, and Ion-Exchange Application. Inorganic Chemistry 2019, 58 (20), 14075-14084.

(21) Li, H. H.; Zeng, X. H.; Wu, H. Y.; Jie, X.; Zheng, S. T.; Chen, Z. R. Incorporating Guest Molecules into Honeycomb Structures Constructed from Uranium(vi)-Polycarboxylates: Structural Diversities and Photocatalytic Activities for the Degradation of Organic Dye. Crystal Growth and Design 2015, 15 (1), 10-13.

(22) Eckert, N. A.; Krause Bauer, J. A.; Connick, W. B. N , N '-Diethyl-4,4'-Bipyridinium Diiodide . Acta Crystallographica Section C Crystal Structure Communications 1999, 55 (9), IUC9900101.

(23) Sheldrick, G. M. A Short History of SHELX. Acta Crystallographica Section A: Foundations of Crystallography. International Union of Crystallography January 1, 2008, pp 112-122.

(24) Hübschle, C. B.; Sheldrick, G. M.; Dittrich, B. ShelXle: A Qt Graphical User Interface for SHELXL. Journal of Applied Crystallography 2011, 44 (6), 1281-1284.

(25) Match! - Phase Analysis using Powder Diffraction, Crystal Impact - Dr. H. Putz \& Dr. K. Brandenburg GbR, Kreuzherrenstr. 102, 53227 Bonn, Germany, https://www.crystalimpact.de/match

(26) Gaussian 16, Revision C.01, Frisch, M. J.; Trucks, G. W.; Schlegel, H. B.; Scuseria, G. E.; Robb, M. A.; Cheeseman, J. R.; Scalmani, G.; Barone, V.; Petersson, G. A.; Nakatsuji, H.; Li, X.; Caricato, M.; Marenich, A. V.; Bloino, J.; Janesko, B. G.; Gomperts, R.;

Mennucci, B.; Hratchian, H. P.; Ortiz, J. V.; Izmaylov, A. F.; Sonnenberg, J. L.; WilliamsYoung, D.; Ding, F.; Lipparini, F.; Egidi, F.; Goings, J.; Peng, B.; Petrone, A.; Henderson, T.; Ranasinghe, D.; Zakrzewski, V. G.; Gao, J.; Rega, N.; Zheng, G.; Liang, W.; Hada, M.; Ehara, M.; Toyota, K.; Fukuda, R.; Hasegawa, J.; Ishida, M.; Nakajima, T.; Honda, Y.; Kitao, O.; Nakai, H.; Vreven, T.; Throssell, K.; Montgomery, J. A., Jr.; Peralta, J. E.; Ogliaro, F.; Bearpark, M. J.; Heyd, J. J.; Brothers, E. N.; Kudin, K. N.; Staroverov, V. N.; Keith, T. A.; Kobayashi, R.; Normand, J.; Raghavachari, K.; Rendell, A. P.; Burant, J. C.; Iyengar, S. S.; Tomasi, J.; Cossi, M.; Millam, J. M.; Klene, M.; Adamo, C.; Cammi, R.; Ochterski, J. W.; Martin, R. L.; Morokuma, K.; Farkas, O.; Foresman, J. B.; Fox, D. J. Gaussian, Inc., Wallingford CT, 2016.

(27) Becke, A. D. Density-Functional Thermochemistry. III. The Role of Exact Exchange. The Journal of Chemical Physics 1993, 98 (7), 5648-5652. 
(28) Lee, C.; Yang, W.; Parr, R. G. Development of the Colle-Salvetti Correlation-Energy Formula into a Functional of the Electron Density. Physical Review B 1988, 37 (2), 785 789.

(29) Weigend, F.; Ahlrichs, R. Balanced Basis Sets of Split Valence, Triple Zeta Valence and Quadruple Zeta Valence Quality for H to Rn: Design and Assessment of Accuracy. Physical Chemistry Chemical Physics 2005, 7 (18), 3297.

(30) Krishnan, R.; Binkley, J. S.; Seeger, R.; Pople, J. A. Self-consistent Molecular Orbital Methods. XX. A Basis Set for Correlated Wave Functions. The Journal of Chemical Physics 1980, 72 (1), 650-654.

(31) Küchle, W.; Dolg, M.; Stoll, H.; Preuss, H. Energy-adjusted Pseudopotentials for the Actinides. Parameter Sets and Test Calculations for Thorium and Thorium Monoxide. The Journal of Chemical Physics 1994, 100 (10), 7535-7542.

(32) Cao, X.; Dolg, M. Segmented Contraction Scheme for Small-Core Actinide Pseudopotential Basis Sets. Journal of Molecular Structure: THEOCHEM 2004, 673 (13), 203-209.

(33) Cao, X.; Dolg, M.; Stoll, H. Valence Basis Sets for Relativistic Energy-Consistent SmallCore Actinide Pseudopotentials. The Journal of Chemical Physics 2003, 118 (2), 487496.

(34) Hanwell, M. D.; Curtis, D. E.; Lonie, D. C.; Vandermeersch, T.; Zurek, E.; Hutchison, G. R. Avogadro: An Advanced Semantic Chemical Editor, Visualization, and Analysis Platform. Journal of Cheminformatics 2012, 4 (1), 17.

(35) Heyd, J.; Scuseria, G. E. Efficient Hybrid Density Functional Calculations in Solids: Assessment of the Heyd-Scuseria-Ernzerhof Screened Coulomb Hybrid Functional. The Journal of Chemical Physics 2004, 121 (3), 1187-1192.

(36) Heyd, J.; Scuseria, G. E. Assessment and Validation of a Screened Coulomb Hybrid Density Functional. The Journal of Chemical Physics 2004, 120 (16), 7274-7280.

(37) Heyd, J.; Peralta, J. E.; Scuseria, G. E.; Martin, R. L. Energy Band Gaps and Lattice Parameters Evaluated with the Heyd-Scuseria-Ernzerhof Screened Hybrid Functional. The Journal of Chemical Physics 2005, 123 (17), 174101.

(38) Henderson, T. M.; Izmaylov, A. F.; Scalmani, G.; Scuseria, G. E. Can Short-Range Hybrids Describe Long-Range-Dependent Properties? The Journal of Chemical Physics 2009, 131 (4), 044108.

(39) Izmaylov, A. F.; Scuseria, G. E.; Frisch, M. J. Efficient Evaluation of Short-Range Hartree-Fock Exchange in Large Molecules and Periodic Systems. The Journal of Chemical Physics 2006, 125 (10), 104103.

(40) Krukau, A. V.; Vydrov, O. A.; Izmaylov, A. F.; Scuseria, G. E. Influence of the Exchange Screening Parameter on the Performance of Screened Hybrid Functionals. The Journal of Chemical Physics 2006, 125 (22), 224106.

(41) Lu, T.; Chen, F. Multiwfn: A Multifunctional Wavefunction Analyzer. Journal of Computational Chemistry 2012, 33 (5), 580-592.

(42) Mooibroek, T. J.; Gamez, P.; Reedijk, J. Lone Pair- $\pi$ Interactions: A New Supramolecular Bond? CrystEngComm 2008, 10 (11), 1501-1515.

(43) Lee, N.-S.; Shin, H.-K.; Kim, Y. J.; Kim, C.-H.; Suh, S.-H. HOMO-LUMO Energy Gap Analysis of Alkyl Viologen with a Positively Charged Aromatic Ring. Rev. Roum. Chim. 2010, 55(10), 627-632 
(44) Denning, R. G. Electronic Structure and Bonding in Actinyl Ions and Their Analogs. Journal of Physical Chemistry A 2007, 111 (20), 4125-4143.

(45) Matheeon, M. S.; Lee, P. C.; Melsel, D.; Pelizzetti, E. Kinetics of Hydrogen Production from Methyl Viologen Radicals on Colloidal Platinum. J. Chem. Phys. 1983, 87, 394-399

(46) Tsukahara, K.; Wilkins, R. G. Kinetics of Reduction of Eight Viologens by Dithionite Ion. Journal of the American Chemical Society 1985, 107 (9), 2632-2635

(47) Ryan, M. D.; Wilson, G. S. Some Considerations in Spectroelectrochemical Evaluation of Homogeneous Electron Transfer Involving Biological Molecules. Analytical Chemistry 1975, 47 (6), 885-890

(48) Bertoncello, P.; Ram, M. K.; Notargiacomo, A.; Ugo, P.; Nicolini, C. Fabrication and Physico-Chemical Properties of Nafion Langmuir-Schaefer Films. Phys. Chem. Chem. Phys. 2002, 4 (16), 4036-4043.

(49) Cowie, B. E.; Purkis, J. M.; Austin, J.; Love, J. B.; Arnold, P. L. Thermal and Photochemical Reduction and Functionalization Chemistry of the Uranyl Dication, $\left[\mathrm{UVIO}_{2}\right]^{2+}$. Chemical Reviews 2019, 119 (18), 10595-10637.

(50) David Allen, B. M.; Burrows, H. D.; Cox, A.; Hill, R. J.; Kemp, T. J.; Stone, T. J. Absorption Spectrum and Reaction Kinetics of the Photoreactive State of the Uranyl Ion. J. Chem. Soc., Chem. Commun. 1973, 2, 59-60.

(51) Richard Hill, B. J.; Allen, D. M.; Cox, A. Absorption Spectrum, Lifetime and Photoreactivity towards Alcohols of the Excited State of the Aqueous Uranyl Ion $\left(\mathrm{UO}_{2}{ }^{2+}\right)$. J. Chem. Soc., Faraday Trans. 1 1974, 70, 847-857

(52) Volman, D. H.; Seed, J. R. The Photochemistry of Uranyl Oxalate. Journal of the American Chemical Society 1964, 86 (23), 5095-5098

(53) Ortu, F.; Randall, S.; Moulding, D. J.; Woodward, A. W.; Kerridge, A.; Meyer, K.; la Pierre, H. S.; Natrajan, L. S. Photoluminescence of Pentavalent Uranyl Amide Complexes. Journal of the American Chemical Society 2021, 143 (33), 13184-13194.

(54) Redmond, M. P.; Cornet, S. M.; Woodall, S. D.; Whittaker, D.; Collison, D.; Helliwell, M.; Natrajan, L. S. Probing the Local Coordination Environment and Nuclearity of Uranyl(vi) Complexes in Non-Aqueous Media by Emission Spectroscopy. Dalton Transactions 2011, 40 (15), 3914-3926.

(55) Yokoyama, Y. U.; Moriyasu, M.; Ikeda, S. Electron Transfer Mechanism in Quenching of Uranyl Luminescence by Halide Ions. J. Inorg. Nucl. Chem. 1976, 38, 1329-1333.

(56) Rehm, D.; Weller, A. Kinetics of Fluorescence Quenching by Electron and H-Atom Transfer. Isreal Journal of Chemistry 1970, 8 (2), 259-271.

(57) Michaelis, L.; Hill, E. S. The Viologen Indicators. J. Gen. Physiol. 1933, 16 (6), 859-873

(58) Cheng, B.; Kaifer, A. E. Electrochemistry of Viologen Dications in Cholate Media and Competition between the Cholate Assemblies and the Cucurbit[7]Uril Host. Langmuir 2015, 31 (10), 2997-3002.

(59) Electrochemical Series. In Corrosion: Materials, ASM International, 2005. 